\title{
Las empresas familiares en la red inter-firmas: el caso de la industria suiza de máquinas y metales en el siglo $X X^{1}$
}

\author{
Stéphanie Ginalski ${ }^{2}$ - Fondo Nacional suizo de Investigación Científica (Fonds
} National Suisse de la Recherche Scientifique) ${ }^{3}$

\begin{abstract}
Esta contribución tiene como objetivo integrar el análisis de las interconexiones entre los consejos de administración (interlocks), método frecuentemente utilizado para estudiar los vínculos entre las empresas, para, en este caso, centrarnos en el tema de las empresas familiares, una aproximación generalmente no tenido en cuenta en estos estudios. Para ello, esta investigación se centra en 22 grandes empresas de la industria suiza de máquinas, de electrotecnia y de metalurgia (MEM), cuyos miembros de los Consejos de Administración y gerentes generales han sido identificados en cinco momentos que abarcan todo el siglo (1910, 1937, 1957,1980 y 2000). El análisis de redes consiste en seguir la evolución de los vínculos mantenidos por estas 22 empresas en el seno de las 110 empresas más grandes de Suiza. Nuestros resultados muestran que hasta la década de los 80 , los interlocks se vuelven vez más densos y representan un mecanismo de coordinación de las élites económicas, las empresas familiares y los dirigentes familiares encontrándose con los bancos en el corazón de este sistema. Las dos últimas décadas del siglo, sin embargo, se caracterizan por la erosión relativa del capitalismo familiar, la retirada del sector bancario en la red entre empresas y la disminución significativa de los interlocks.
\end{abstract}

Palabras clave: redes empresariales, capitalismo familiar, maquinaria, metalurgia, Suiza, Siglo XX.

\section{Introduction}

El análisis de las interconexiones entre los consejos de administración (interlocks), formadas por los miembros comunes a las empresas, es un método frecuentemente empleado para el estudio de las relaciones entre grandes empresas. En una contribución que sintetiza la cuestión, Mizruchi muestra de manera convincente que, "although they are not the answer to all questions about interorganizational relations, interlocks remain a powerful indicator of network ties between firms" (1996: 272). En esta perspectiva, numerosas investigaciones se han interesado, por ejemplo, en los vínculos entre las empresas industriales y los bancos; otras han

\footnotetext{
${ }^{1}$ Artículo traducido por Nathaly Cruz, Lola de la Rúa y Ainhoa de Federico.

2 Agradezco a Claire Lemercier, Thomas David, André Mach así como a los tres expertos anónimos por sus comentarios sobre una primera versión del artículo.

${ }^{3}$ Enviar la correspondencia a: Stéphanie Ginalski Stephanie.Ginalski@unil.ch
} 
puesto incluso en evidencia el rol de los interlocks en los procesos de cartelización. Esta contribución se propone, por su parte, abordar la cuestión de las redes de interconexiones entre empresas bajo el ángulo del capitalismo familiar. En efecto, diversas investigaciones recientes han puesto en evidencia la fuerte supervivencia del capitalismo familiar, históricamente ligado a la primera revolución industrial, a los capitalismos gerencial y financiero que le han sucedido en la mayor parte de los países llamados desarrollados (ver especialmente Colli 2003, Daumas 2003, James 2006 y Colli \& Rose 2008). Ahora bien, este aspecto ha sido generalmente poco tenido en cuenta en las investigaciones que han recurrido al análisis de redes para estudiar las relaciones entre empresas y, en ciertos casos, estas redes han sido incluso aprehendidas como estructuras que han reemplazado los vínculos familiares: "As a means to coordinate business transactions, the corporate network spread throughout the entrepreneurial world, thereby supplanting family ties" (Windolf 2009: 443). Por el contrario, "Los estudios que implican la historia de la familia -que la familia sea el objeto o que las relaciones familiares y las alianzas jueguen un rol explicativo importante- pocas veces dejan lugar a la utilización del análisis de red [...]" (Lemercier 2005: 23). El análisis de redes permanece en particular como un método poco empleado en los estudios que tratan sobre el capitalismo familiar, los cuales existen frecuentemente bajo la forma de monografías de empresas. Sin embargo, éste puede mostrarse como una herramienta muy útil para salir del estudio de caso, hacia el que tiende típicamente la monografía de empresa, e intentar una interpretación más amplia de la evolución del capitalismo familiar. En efecto, Colli recordó recientemente, en un artículo titulado "Business History in Family Business Studies", "the need of moving from the mud of (even if absolutely necessary) individual cases to generalizations" (2010 por publicar [1] $)^{4}$. Etudiar las empresas familiares por la vía de un análisis de red permite además poner en evidencia su integración en un sistema capitalista más amplio, más que observarlas como otro objeto de estudio. En esta perspectiva, el caso suizo presenta un interés particular. Por una parte, se observa una fuerte persistencia del capitalismo familiar al final del siglo XX en comparación con otros países occidentales, incluso en las grandes sociedades cotizadas en bolsa (La Porta et al. 1999, Ernst \& Young 2005); el tema permanece sin embargo relativamente poco estudiado en lo que concierne al periodo contemporáneo, y la mayor parte de las investigaciones existen bajo la forma de monografías que tratan sobre un

\footnotetext{
${ }^{4}$ Citado con la autorización del autor.
} 
individuo, una familia o una empresa. Por otra parte, el país se caracteriza por un "capitalismo cooperativo" (Schröter 1999: 192) durante la mayor parte del siglo, y forma claramente parte, al igual que Alemania por ejemplo, de las economías de mercado llamadas coordinadas que se caracterizan por mecanismos de cooperación entre los actores económicos y políticos, en oposición a las economías dichas liberales que funcionan esencialmente sobre un principio competitivo (Hall \& Soskice 2001). Las redes de interconexiones entre empresas pueden, en esta perspectiva, ser percibidas como una de estas formas de regulación colectiva, y los vínculos entre las empresas son en consecuencia generalmente más densos en una economía de tipo coordinado que en una economía liberal (Höpner et Krempel 2003, Windolf et Nollert 2001). Diversos estudios han mostrado en efecto, para el caso helvético, la existencia de una importante red de interconexiones entre las grandes empresas del país (Schreiner 1984, Rusterholz 1985, Nollert 1998, Schnyder et al. 2005; para el sector de la metalurgia, ver Widmer 2009). Hasta la fecha, estas contribuciones se han focalizado, no obstante, esencialmente en el rol y el lugar de los bancos; y pocas veces se ha evocado la cuestión de las familias, o de las empresas familiares.

En vista de la importancia del capitalismo familiar y de las redes de interconexiones en Suiza, parece pertinente interrogarse sobre la posición de las empresas familiares y de los dirigentes familiares en el seno de esta red inter-empresas. Bajo esta perspectiva, esta contribución se centra en las grandes empresas del sector de la maquinaria, la ingeniería electro-técnica y la metalurgia (en adelante MEM), que representa desde el periodo entre-guerras la principal rama industrial del país en términos de exportaciones y de mano de obra empleada (Billeter 1985): constituye así, en una perspectiva histórica, el sector industrial más importante del siglo XX. Estudiar a los dirigentes de la rama MEM permite en consecuencia analizar la "cumbre" de la élite económica suiza. Partimos de la hipótesis según la que esta élite dirigente representa un grupo económico fuertemente organizado, y de que esta organización pasa especialmente por una red de interconexiones entre los consejos de administración de las empresas (Widmer 2009), y abrimos una nueva pista de investigación poniendo en evidencia el lugar de las empresas familiares en el seno de este sistema coordinado, y su evolución en el curso del siglo XX. Para ello, esta investigación enfoca la sub-red constituida por los vínculos sostenidos por 22 grandes sociedades MEM en el seno de las 110 empresas suizas más grandes. La primera parte del análisis muestra que esta sub-red reposa fuermente sobre las empresas familiares y sobre los dirigentes familiares hasta los años 1980, habiendo sido marcado el fin de siglo a su vez por la erosión relativa del capitalismo familiar, 
y por la decadencia significativa de los interlocks. La segunda parte de la investigación se concentra sobre los vínculos múltiples entre las empresas, con el fin de analizar de manera más cualitativa los mecanismos de cooperación en el seno del sector MEM por la vía de los interlocks. Se evidencian las fuertes interconexiones entre las empresas MEM y el sector bancario desde inicios del siglo y hasta los años 1980, sin embargo progresivamente suplantadas por el importante desarrollo de los vínculos intrasectoriales que vienen así a confirmar la hipótesis de una coordinación patronal anclada al menos en parte a las redes interempresas. Además, el mantenimiento relativo de los vínculos intrasectoriales a final del siglo nos permite relativizar la decadencia más general de los interlocks en el curso de este periodo.

\section{Red de empresas y capitalismo familiar en Suiza. Redes y poder económico}

El análisis de las redes de interconexión entre los consejos de administración es un método corrientemente empleado para estudiar los vínculo entre empresas (para una síntesis, ver Mizruchi 1996). Se puede tomar prestada de Scott la siguiente definición fundamental de vínculo de interconexión: «An interlock is simply the social relation that is created between two enterprises when one person is a member of the board of directors in each enterprise. Such a person is termed a multiple director » (Scott 1985: 1). La apuesta consistirá entonces en interpretar este vínculo, y, sobre todo, en darle un sentido en términos de poder económico. Dos modelos en particular, entre los propuestos por el autor, presentan un interés en nuestro tema: el "co-ordination and control model" y el "class-cohesion model" (Scott 1985: 6ff). El primero, que se puede traducir por «modelo de coordinación y de control», se concentra en los vínculos entre empresas, y conoce dos variantes: el control por los bancos, y el control por las familias. El modelo de control por los bancos significa que estos últimos representan los centros de decisión en la red; se aplica particularmente bien en los países caracterizados por una economía coordinada, en los cuales los bancos están de manera tradicional fuertemente implicados en las empresas industriales por la vía de la acción de crédito. En estos países, los bancos ocupan así generalmente un lugar central en la red interempresas (Stokman \& Wasseur 1985). En el modelo de control familiar, "the central positions in the network would be taken by family investment or holding companies, each of which would lie at the centre of a clique or cluster." Este modelo postula, además, que los vínculos entre los directores múltiples son potentemente articulados alrededor de las familias, desconectadas unas de otras (Scott 1985: 9). El segundo modelo, que se puede traducir por "modelo de cohesión de clase", "holds that directors are recruited from an upper class and that 
the patterns of interlocks express and contribute to the cohesion of this class. [...] Interlocks simply map the cohesion of the capitalist class" (Scott 1985: 11). En esta perspectiva, la cohesión de la red inter-empresas ilustra y refuerza la de la élite dirigente, y los actores que acumulan diversos mandatos en diferentes consejos de administración, los big linkers, detentan un poder acrecentado en el seno de la comunidad económica. La influencia de este restringido círculo de élite, definido por Mills (1969) como la "élite del poder", o como "I'inner circle" por Useem (1984), no se limita además al mundo económico, sino que se extiende igualmente a la esfera política.

\section{El lugar central de los bancos en la red de empresas suizas}

Algunos estudios ya han puesto en evidencia las principales características de la red de interconexiones entre los consejos de administración de las grandes empresas suizas. La primera investigación que ha recurrido a un análisis sistemático de los vínculos entre los consejos de administración es la de Schreiner (1984) realizada sobre 36 grandes empresas tomadas de los sectores bancario, seguros e industrial para el año 1980. Esta contribución ha evidenciado por una parte la fuerte imbricación existente entre las sociedades financieras y las empresas industriales, y por otra parte la posición central ocupada por los bancos y las compañías de seguros en la red. El autor relativiza no obstante, la hipótesis de un capitalismo dominado por los bancos, mostrando que esa red constituye "una estructura centralizada pero no exclusiva que será una prueba de la capacidad de las grandes sociedades suizas para establecer un modo de toma estratégica de decisiones coordinada, excluyendo al máximo los conflictos entre los diferentes componentes de la red" (91). Además concluye: "existen (...) ciertas presunciones que nos hacen inclinar hacia un modo de estructuración del capital financiero helvético bajo una forma oligárquica a causa de la influencia de la propiedad familiar en la mayor parte de las grandes sociedades" (Schreiner 1984: 93). Estas afirmaciones permanencen sin embargo en un estado de "presunción", puesto que la cuestión de la propiedad familiar es más puntualmente evocada que integrada de manera sistemática en el análisis de los vínculos de interconexiones entre las empresas. Esto es así también para la cuestión del «juego de solidaridades familiares» mencionado por el autor y hace referencia, de manera un poco confusa, a su vez, a la presencia de la dinastía fundadora en la empresa familiar, y a su proyección en las otras sociedades (91). Pese a sus limitaciones, este estudio tiene el mérito de abrir dos pistas interesantes de investigación: la de los vínculos banca-industria, y la del ámbito del capitalismo familiar. Ésta es sobre todo la primera dimensión que hasta el presente ha sido objeto de investigaciones ulteriores. Así, el estudio de Rusterholz (1985), basado 
en las 250 empresas más grandes para el año 1976, muestra que la red posée en ese momento una estructura casi densa y fuertemente centralizada alrededor de los tres bancos más grandes del país: La Sociedad de Bancos Suizos (Société des Banques Suisses - SBS), La Unión de Bancos Suizos (Union des Banques Suisses UBS) y el Crédito Suizo (Crédit Suisse - CS) y de la Banca Nacional Suiza (Banque Nationale Suisse - BNS). En su análisis concerniente a las 300 empresas helvéticas más grandes para el año 1995, Nollert confirma el lugar central de los bancos en la red: "Hence, the network structure has changed little over two decades. [...] the findings largely support the bank hegemony model" (Nollert 1998: 45). Pone además en evidencia la existencia de una red de big linkers fuertemente cohesiva, lo que confirma, para el caso suizo, la existencia de un «inner circle » (Nollert 1998: 49). En cuando al estudio de Schnyder et al. (2005), éste integra por primera vez una perspectiva diacrónica al análisis de la red inter-empresas, interesándose en la evolución de los vínculos entre las 110 empresas helvéticas más grandes en el curso del siglo XX. Los autores distinguen así tres fases: la emergencia y la formación de vínculos durante el primer tercio de siglo, su consolidación hasta los años 1980, y su fuerte decadencia durante los dos últimos decenios. Aunque sus resultados confirman el rol central jugado por los bancos en esa red durante la mayor parte del siglo, los autores relativizan sin embargo la hipótesis de un control formal de los bancos sobre las empresas (bank control model), demostrando que los vínculos son de hecho con frecuencia de naturaleza recíproca: los banqueros participan en los consejos de las grandes industrias, así como los industriales participan igualmente en los consejos de los bancos a los cuales están ligados (Schnyder et al. 2005 : 53 ; sur ce point, voir également Nollert 1998 : 53-54). Además, su estudio muestra una ruptura mayor en el transcurso del último decenio, ligada a la liberación progresiva de los bancos en relación al sector industrial, lo cual explica en gran parte la fuerte decadencia de los vínculos en el centro de la red. Finalmente, Widmer (2009) ha mostrado en su tésis, sobre la coordinación de los dirigentes MEM para el periodo 1970-2008, que los dirigentes de dicho sector representan un grupo económico fuertemente organizado por la vía de organizaciones patronales, de una parte, y a través de una red densa de interconexiones entre los consejos de administración de las principales empresas, de otra, pese a que se constata igualmente un declive de los vínculos al final del periodo considerado. 


\section{La fuerte persistencia del capitalismo familiar en Suiza}

Hasta el presente, los estudios sobre las grandes empresas suizas, habiendo tenido como recurso un análisis de redes, están principalmente enfocados en el rol y en el lugar de los bancos, y la cuestión de las empresas familiares se ha dejado de lado. En vista de la fuerte persistencia del capitalismo familiar en Suiza durante el siglo $X X$, el objetivo de esta contribución está en explorar esta nueva pista de investigación. Se distinguen tres modos sucesivos de gobernanza de empresa, ligados a tres formas de capitalismo: el capitalismo familiar, gerencial y financiero (Para una síntesis, ver por ejemplo Batsch 2002). El capitalismo familiar recubre, históricamente el primero de tales modos. Éste está tradicionalmente asociado a la primera revolución industrial, durante la cual las empresas nacientes estuvieron poseídas y dirigidas por las familias. Con la segunda revolución industrial apareció la empresa gerencial, más intensiva en capital, y varios autores vieron en el capitalismo familiar una forma de gobernanza destinada a desaparecer, por la apertura al público del capital de las sociedades. Para Berle \& Means (1932), la multiplicación del número de propietarios resulta, en efecto, en la separación de las funciones entre propiedad y control y, a partir de ésta, en la pérdida de poder de los accionistas en beneficio de los gerentes. Esta hipótesis se refleja en varias décadas, particularmente en las investigaciones de americanos. Para Chandler, la complejidad creciente de la empresa moderna habría llamado a una creciente profesionalización de gerentes, las competencias técnicas habrían reemplazado al final a los vínculos familiares para acceder a las funciones dirigentes de la empresa (Chandler 1977). Según este autor, es el mantenimiento de un capitalismo familiar o "personal" en Gran Bretaña lo que habría impedido a esta última mantenerse competitiva frente a sus competidoras en el transcurso de la segunda revolución industrial (Chandler 1990). Si se supone que el capitalismo gerencial suplantó al capitalismo familiar, se asistiría, a partir del final de los años 1970 y en los Estados Unidos en primer lugar, a la emergencia de una nueva forma de capitalismo calificado de «accionista» o de «financiero», dominada por los fondos de investigación y caracterizado por una reorientación de las estrategias de las empresas a favor de la creación del «valor accionista», concerniente a una mejor retribución del accionista (ver especialmente Useem 1996 ; Lazonick \& O'Sullivan 2000 ; Lordon 2000 ; Rebérioux 2005).

Muchos autores han mostrado sin embargo que el capitalismo familiar ha sabido, en parte al menos, «sobrevivir» a los capitalismos gerencial y financiero que lo han sucedido en la mayoría de los países llamados desarrollados (ver especialmente Colli 2003, Daumas 2003, James 2006 y Colli \& Rose 2008). Esta constante se 
aplica igualmente al caso de Suiza. De hecho, el estudio de La porta et al. (1999), que compara el lugar de las empresas familiares entre las 20 más grandes sociedades cotizadas en bolsa en 27 países con diferentes niveles de desarrollo, muestra que a mediados de los años 1990, el 30\% de las grandes empresas helvéticas cotizadas en bolsa pueden ser consideradas como empresas familiares. Estos datos se limitan, sin embargo, a las 20 más grandes sociedades cotizadas: De hecho, en el inicio de los años 2000, la parte de las empresas familiares entre las sociedades helvéticas está estimada globalmente en 88,4\%, "un índice elevado comparado con el resto del mundo" (Ernst \& Young 2005: 6). Este porcentaje se eleva a $70 \%$ en lo que concierne a las grandes empresas (es decir con más de 250 empleados), y a $37 \%$ en lo que concierne a las sociedades cotizadas en bolsa (Ernst \& Young 2005: 4 y 11).

El marco legislativo relativamente permisivo en materia de gobernabilidad de empresa, hasta la introducción de recientes reformas (revisión del derecho de las SA de 1992 y nueva ley federal sobre la bolsa de 1995), ha dejado un gran espacio a la autorregulación de los actores económicos y representa, en nuestra opinión, el factor principal que permite explicar esta supervivencia del capitalismo familiar para el caso de Suiza. La existencia de ciertos instrumentos, como la posibilidad de emitir diferentes categorías de acciones permite a los propietarios poseer la mayoría de derechos de voto sin poseer forzosamente la mayoría de las acciones, o limitar la transferibilidad de las acciones nominativas en los «vínculos» a su propietario y mediante la imposición de ciertas condiciones a los nuevos compradores (Vinkulierung), permitieron a ciertas familias conservar la empresa en propiedad, pese a su apertura al público (Schnyder 2007 y David et al. 2012 por publicarse). Muchas de las grandes empresas han permanecido así en el transcurso del siglo XX bajo la dominación de un gran accionista, o de un pequeño grupo de accionistas, siendo esta dimensión fortalecida por la débil participación de los empleados en la empresa y por la marginalización de los accionistas minoritarios (David et al. 2012 por publicarse). En consecuencia, el capitalismo helvético se distingue por una fuerte concentración del poder y de la propiedad, ligada a la importancia de la propiedad familiar e individual (Windolf y Nollert 2001).

Varios autores se han interesado así en el peso de las familias en las esferas económica y política suizas en el siglo XX (ver especialmente Giovanoli 1939, Pollux 1945, Holliger 1974 y Höpflinger 1978). Tales estudios son sin embargo relativamente antiguos; además, nunca han utilizado un análisis de red, a pesar de algunas pistas prometedoras destacadas por ciertas investigaciones. Por ejemplo, la tesis reciente de Alain Cortat sobre el cartel suizo de los cables ha mostrado, sin 
haber empleado un análisis de red propiamente dicho, cómo no solamente los vínculos entre los consejos de administración, sino también los vínculos familiares están en este caso "en el origen de los acuerdos que coordinan aspectos de la economía y particularmente de los acuerdos de carteles y de control de precio" (Cortat 2009: 23). En el marco de esta contribución, nos interesamos en el rol de la familia específicamente bajo el ángulo de las empresas familiares, cuya definición, lejos de ser simple y estandarizada, se discute en el siguiente capítulo.

\section{Método y Fuentes}

La principal dificultad para abordar la cuestión del capitalismo familiar reside en el hecho de que su definición no es en sí misma evidente: «The definition of family firms is in fact highly subjective and far from being standardised» (Colli 2003: 17). Por ejemplo, el estudio de la Porta et al. (cf. arriba) define como familiar a una empresa controlada por una familia o por un accionista individual poseedor directa o indirectamente del 20\% de los derechos de voto (La Porta et al. 1999: 476). Este trayecto, por otro lado comúnmente adoptado, presenta, a nuestro juicio, dos problemas: primeramente, sólo tiene en cuenta la cuestión del control y, en segunda instancia, incluye en la definición de la empresa familiar a los accionistas individuales. Por su parte, la definición adoptada en el marco de esta contribución retoma, para comenzar, la distinción hecha por varios autores entre control y dirección ${ }^{5}$ (ver especialmente Casson 2000, Colli 2003 y Colli \& Rose 2008). En esta perspectiva, el control familiar vuelve a la situación en la que la familia detenta suficientes derechos de voto, u ocupa suficientes escaños en el consejo de administración para ejercer influencia sobre las decisiones del director general; la dirección familiar vuelve por su parte a la situación en la que un miembro de la familia ejerce la función de director general. Al no ser accesible la composición del accionariado de las empresas suizas para la mayor parte del periodo que nos interesa, hemos seleccionado, dependiendo del caso, la presencia de la familia en el consejo de administración como indicador de una empresa probablemente controlada por una familia. En lo que concierne a la cuestión de la dirección, hemos estimado que ésta podría ser calificada de familiar a partir del momento en que un miembro de la familia ocupe una función dirigente decisiva en la empresa (presidente del consejo de administración, administrador-delegado o director general). Finalmente, hemos dado un peso preponderante a la cuestión de la

\footnotetext{
${ }^{5}$ Precisemos que los autores citados recurren a las denominaciones inglesas possession et control, que indican para nosotros respectivamente a los téminos control y dirección (contróle et direction).
} 
dirección de la empresa (ver especialmente Colli 2003: 20), estimando que la presencia de la familia en el seno de las posiciones ejecutivas-clave era significativo de un capitalismo familiar «fuerte», mientras que el control sólo implicaba un capitalismo familiar « medio ».

Nuestra definición del capitalismo familiar integra, además, como criterio determinante, como en el caso de Joly, la dimensión de la transmisión de las funciones de poder al interior de una misma familia: «Comporta una dimensión familiar toda empresa en la cual al menos una parte de las posiciones de poder se transmita, en relación o no con la propiedad del capital, por la vía de la herencia familiar » (2008: 66). En esta perspectiva, el criterio de la presencia de al menos dos personas de una misma familia, ya sea coincidente con una misma fecha o sucesiva entre dos fechas diferentes, en una misma generación o entre generaciones diferentes, ha sido escogido para atribuir el calificativo de familiar, trátese de la dinastía fundadora o de una nueva familia que haya tomado el control - la posesión de la empresa ulteriormente (sobre la cuestión de los «neofundadores », ver especialmente Joly 2008). Sobre la base de esta tipología, hemos determinado la presencia familiar en 22 grandes empresas del sector MEM en Suiza. Estas empresas han sido seleccionadas a partir de una base de datos sobre las élites suizas, que presenta entre otros aspectos, los miembros del consejo de administración y los directores generales de las 110 más grandes empresas helvéticas en cinco fechas que cubren el siglo XX: 1910, 1937, 1957, 1980 y $2000 .^{6}$ Todas las empresas del sector MEM que aparecen en al menos una fecha en esta base de datos han sido seleccionadas, a condición de que éstas perduren durante todo el siglo (ver anexo 1); las empresas creadas después de 1910, o que desaparecen antes de 2000, han sido excluidas con el fin de tener una muestra estable en el largo plazo. ${ }^{7}$ Los miembros de los consejos de administración y los dirigentes ejecutivos han sido registrados principalmente a partir de los informes anuales de las empresas, y a falta de éstos, con la ayuda de fuentes complementarias, tales como los registros de comercio, y de fuentes secundarias, a

6 Esta base de datos ha sido configurada en el marco de un proyecto de investigaciôn financiado por el Fondo Nacional Suizo para la Investigaciôn Scientîfica (FNRS por su nombre en francés) sobre las élites suizas en el siglo XX. El proyecto $y$ la base son consultables en la direcciôn: http://www.unil.ch/iepi/page54315.html

7 Excepción hecha para Cortaillod, Cossonay, Landis \& Gyr y Von Moos, que desaparecen en el curso de los anios 1990 pero que han sido conservadas, en vista de la gran importancia que éstas han representado en el paisaje económico de Suiza durante la mayor parte del siglo. El anâlisis trata así sobre 18 empresas para el año 2000. 
saber, principalmente de monografías de empresa. En lo concerniente a la cuestión de la dimensión familiar, hemos tenido información principalmente en los Almanaques Genealógicos suizos (Schweizerisches Geschlechterbuch, SGB), compuestos por doce volúmenes publicados entre 1905 y 1965, y en los Almanaques de las Familias Suizas (Schweizerisches Familienbuch, SFB) compuestos por cuatro volúmenes publicados entre 1945 y 1963, a fin de identificar los vínculos familiares entre los miembros de las empresas que hemos escojido. Los primeros han sido concebidos inicialmente para seleccionar las familias aún existentes de la antigua Confederación habiendo «tenido un lugar remarcable en la historia, de las familias Ilamadas "reinantes" o cuyos títulos estaban basados en el derecho público de la época» (SGB 1951: XI). Estos registran entonces esencialmente, hasta el volumen VIII, a las antiguas familias pertenecientes a la nobleza suiza. Los volúmenes siguientes tienen por su parte una nueva sección en que figuran las familias dirigentes más importantes del nuevo estado federal, sobre el mismo principio que el Almanaque de las Familias Suizas. Estos datos han sido completados, de nuevo, cuando ha sido necesario, por fuentes secundarias, especialmente monografías de empresa y otras que tratan sobre las familias que nos interesaban. Se han identificado todas las personas descendientes de la familia fundadora o neo-fundadora en la medida de lo posible. Además, los individuos que han formado parte de una familia por la vía de una alianza matrimonial (en este caso los yernos, pues las mujeres no ocupan posiciones de poder durante todo el siglo) han sido igualmente tenidos en cuenta. Como en el caso de Zeitlin et al. (1974), nuestra investigación intenta así poner en evidencia en la red interempresas lo que los autores definen como un « kincon group » : «La "unidad efectiva familiar" puede incluir parientes cercanos (secundarios y terciarios) y otros parientes fuera de la familia directa que sin embargo son miembros esenciales de la red extensa y densamente organizada que controla una empresa dada $\gg^{8}(108)$; el « kincon group » representa así « una unidad de parentesco compleja en que los intereses económicos y los lazos familiares están inextricablemente entretejidos $»^{9}$ (109).

\footnotetext{
8 « The "effective kinship unit" may include close relatives (secondary and tertiary) and other kin outside the immediate family who are nevertheless essential members of the extended and tightly organized network that controls a given corporation» (108); el « kincon group» representa así « a complex kinship unit in which economic interests and kinship bonds are inextricably intertwined »

9 « a complex kinship unit in which economic interests and kinship bonds are inextricably intertwined »
} 
Tras haber distinguido, para cada una de las 22 empresas seleccionadas en la muestra y para cada fecha, las empresas controladas por una familia, las dirigidas por una familia, y aquellas para las cuales se puede estimar que la empresa no es familiar sobre la base de la tipología expuesta precedentemente, ${ }^{10}$ el análisis de red trata sobre la sub-red formada por los vínculos mantenidos por las 22 sociedades MEM en el seno de las 110 empresas suizas más grandes: al final, la sub-red que nos interesa está constituída por el cúmulo de redes ego de las 22 empresas MEM. El análisis está por tanto articulado sobre dos ejes principales, complementarios. El primero pretende mostrar el área de influencia de las familias en el seno de esta sub-red, identificando por un lado los interlocks (miembros comunes entre los consejos de administración) creados por las empresas familiares y, por el otro, los eventuales vínculos familiares suplementarios que podrían formarse con miembros de la familia que participen únicamente en otras empresas que aquella controlada o dirigida por su propria familia. Reconociendo ciertos estudios que han subrayado la importancia de los big linkers y, sobre esta base, la pertinencia del modelo de cohesión de clase (cf. más arriba) en la red helvética interempresas, esta parte de la investigación identifica igualmente la evolución del peso de estos actores a lo largo del siglo, definidos en esta investigación como los miembros de las empresas MEM que acumulan al menos tres mandatos en los consejos de administración o en tanto que director general de las 110 más grandes empresas suizas, y el lugar que ocupan los dirigentes familiares. A fin de no sobrepasar el marco de esta contribución, la parte que trata sobre los big linkers se limita no obstante a identificar a estos actores, sin desarrollar la cuestion de su pertenencia de clase o de su implicación en la esfera política, que representa en sí un objeto de estudio. La segunda parte del análisis se concentra por su parte en los vínculos múltiples, a fin de mostrar el modelo de coordinación y control (bank-control y family-control) presentado con anterioridad: «Intuitivamente, las líneas múltiples entre los nodos [...] indican relaciones más cohesivas $\gg^{11}$ (de Nooy et al. 2005). Aplicado a las redes de relaciones entre empresas, el análisis de los vínculos multiples es así mejor para rendir cuenta directamente de un proceso de cooperación entre las empresas: « Los interlocks múltiples entre empresas indican una fuerte relación entre dos empresas y pueden indicar un sistema de cooptación compartido, lo que indica una fuerte

10 Los resultados de esta parte de la investigación han sido objeto de contribuciones precedentes (ver especialmente Ginalski 2010) y son presentadas de manera sintética en el anexo 1.

11 «Intuitively, multiple lines between vertices [...] indicate more cohesive ties » 
posibilidad de que existauna coordinación de políticas e información compartida $\gg^{12}$ (Stokman \& Wasseur 1985: 24). Solo las sociedades que comparten al menos dos miembros en común (red 2-slices) se han tenido en cuenta en esta parte, que tiene por objetivo principal identificar la evolución de los vínculos que las sociedades MEM mantienen en el seno de su propio sector, por una parte, y con el sector bancario, por la otra.

\section{Interlocks y vínculos familiares en la red interempresas MEM}

Esta primera parte del análisis tiene como propósito poner en evidencia la integración de las empresas familiares en la sub-red MEM, concentrándose sobre los vínculos desarrollados por los miembros comunes entre los consejos de administración y sobre los eventuales vínculos familiares suplementarios. Éste muestra que hasta los años 1980, los vínculos se consolidan y se densifican, apoyándose en gran parte sobre las empresas familiares y los dirigentes familiares. El fin de siglo está sin embargo marcado a la vez por la erosión del capitalismo familiar y la decadencia de los vínculos.

\section{Caracteristicas generales de la sub-red MEM}

Nuestros resultados muestran que la sub-red sigue globalmente la misma evolución que la red más grande en la que se inserta: se observa una primera fase de formación de vínculos (1910-1937), seguida por un periodo de consolidación (19371980), antes de un claro declive al final de siglo (1980-2000) (cf. Schnyder et al. 2005). En efecto, hasta los años 1980, el número medio de vínculos por empresa que forma parte de la sub-red (average degree ${ }^{13}$ ) aumenta de manera constante, así como el número total de empresas conectadas a las 22 empresas MEM; luego, al final del siglo, estos indicadores se reducen de manera significativa, e incluso recaen por debajo del nivel de 1910 (cf tabla 1 ). Se constata ademas que en 1910, en 1937 y, en menor medida, en 1957, ciertos miembros de las familias a la cabeza de las 22 empresas MEM ejercen únicamente función en una empresa distinta a

\footnotetext{
12 «Multiple interlocks between corporations indicate a strong relation between two corporations and may indicate a shared system of co-optation, which gives strong possibilities of policy co-ordination and shared information »

13 Como de Nooy et al. (2005: 64) lo han puesto en evidencia, el grado medio (average degree) "es una medida mejor de la cohesión global que la densidad porque no depende del tamaño de la red" ("is a better measure of overall cohesion than density because it does not depend on network size"). Dado que en el caso que nos interesa, el tamano de las redes varía efectivamente de un año a otro, éste ha sido el índice mantenido más que el de la densidad.
} 
aquella dirigida o controlada por los miembros de sus familias ("vínculos familiares"). Teniendo en cuenta estos vínculos, el average degree y el número de empresas conectadas a las 22 sociedades MEM aumentan ligeramente (cf. tabla 1, lineas vínculos cda y vínculos familiares).

\begin{tabular}{|l|c|c|c|c|c|}
\cline { 2 - 6 } \multicolumn{1}{l|}{} & $\mathbf{1 9 1 0}$ & $\mathbf{1 9 3 7}$ & $\mathbf{1 9 5 7}$ & $\mathbf{1 9 8 0}$ & $\mathbf{2 0 0 0}$ \\
\hline $\begin{array}{l}\text { Tamaño medio del cda (22 } \\
\text { empresas MEM) }\end{array}$ & 6,0 & 7,1 & 7,6 & 9,0 & 7,9 \\
\hline $\begin{array}{l}\text { Average degree (sólo vínculos } \\
\text { cda) }\end{array}$ & 4,8 & 6,8 & 7,4 & 8,5 & 4,4 \\
\hline $\begin{array}{l}\text { Average degree (vínculos cda y } \\
\text { vínculos familiares) }\end{array}$ & 4,9 & 7,0 & 7,4 & 8,5 & 4,4 \\
\hline $\begin{array}{l}\text { Número total de empresas } \\
\text { ligadas a las 22 empresas MEM } \\
\text { (sólo vínculos cda) }\end{array}$ & 48 & 55 & 58 & 62 & 49 \\
\hline $\begin{array}{l}\text { Número total de empresas } \\
\text { ligadas a las 22 empresas MEM } \\
\text { (vínculos cda y vínculos } \\
\text { familiares) }\end{array}$ & 51 & 59 & 60 & 62 & 49 \\
\hline
\end{tabular}

(Cda : consejo de administración)

Tabla 1. Características generales de la sub-red de las 22 empresas MEM.

La densificación de los vínculos hasta los años 1980 se explica, por una parte, por el tamaño creciente de las empresas, lo que conlleva a un aumento progresivo del tamaño del consejo de administración hasta los años 1980 (cf. tabla 1), favoreciendo así potencialmente un mayor número de interconexiones. Pero, para que la red se densifique, debe haber igualmente, en paralelo, un crecimiento del número de miembros comunes entre las empresas: ahora bien, la proporción de administradores vinculados a una sola empresa disminuye efectivamente de manera constante hasta los años 1980, lo cual significa que los nuevos miembros han sido reclutados en gran parte entre otros consejos de administración (cf. tabla 2). En este sentido, la densificación de la red implica una selección estratégica por parte de los actores. Este cúmulo creciente de mandatos, que por otra parte no se limita al sector MEM pero que concierne a toda la red de las 110 empresas más grandes, ha sido posible especialmente gracias al débil marco legislativo, que no ha limitado por ejemplo el número de puestos que un administrador podía ocupar. En efecto, mientras que Alemania, por ejemplo, introduce una limitación del número de mandatos al inicio de los años 1930, en Suiza, las propuestas de enmienda de la izquierda en esta dirección han sido rechazadas por la mayoría de la derecha del Parlamento durante la revisión del derecho de las SA de 1936 (David et al. 2011 a 
publicarse: [246]). La disminución del cúmulo de mandatos al final de siglo se explica principalmente por una reorientación de las estrategias de las empresas en favor del valor accionista (ver infra).

\begin{tabular}{|l|c|c|c|c|c|}
\cline { 2 - 6 } \multicolumn{1}{c|}{} & $\mathbf{1 9 1 0}$ & $\mathbf{1 9 3 7}$ & $\mathbf{1 9 5 7}$ & $\mathbf{1 9 8 0}$ & $\mathbf{2 0 0 0}$ \\
\hline 1 mandato & $68,9 \%(91)$ & $57,4 \%(81)$ & $49,0 \%(77)$ & $44,9 \%(79)$ & $60,0 \%(72)$ \\
\hline 2 mandatos & $12,9 \%(17)$ & $14,9 \%(21)$ & $21,7 \%(34)$ & $25,0 \%(44)$ & $20,0 \%(24)$ \\
\hline$\geq 3$ mandatos & $18,2 \%(24)$ & $27,7 \%(39)$ & $29,3 \%(46)$ & $30,1 \%(53)$ & $20,0 \%(24)$ \\
\hline Total interlockers & $31,1 \%(41)$ & $42,6 \%(60)$ & $51,0 \%(80)$ & $55,1 \%(97)$ & $40,0 \%(48)$ \\
\hline $\begin{array}{l}\text { Total } \\
\text { administradores }\end{array}$ & $100 \%(132)$ & $100 \%(141)$ & $100 \%(157)$ & $100 \%(176)$ & $100 \%(120)$ \\
\hline
\end{tabular}

(Entre paréntesis, número de personas)

Tabla 2. Reparto del número de mandatos ocupados en las 110 empresas suizas más grandes entre los miembros de las 22 empresas MEM. Densificación de los vínculos y persistencia del capitalismo familiar (1910-1980).

Las figuras 1 a 5, a continuación, muestran de qué manera los vínculos se articulan en las cinco fechas consideradas. Las 22 empresas MEM se muestran en amarillo, siendo su tamaño proporcional al grado de capitalismo familiar, según la tipologia presentada arriba: el mayor tamaño indica las sociedades dirigidas por un miembro de la familia, el tamaño medio designa aquellas que son solamente controladas por ésta última, mientras que el menor tamaño significa que no se trata de una empresa familiar (nótese que la dimensión familiar sólo se presenta para estas 22 empresas MEM). Los vínculos formados por los miembros comunes entre los consejos de administración se muestran en azul, sin tener en cuenta los multiples vínculos que son objeto de la segunda parte del análisis: así, incluso si dos empresas tienen varios miembros en común, la relación se indica por un vínculo simple. Los vínculos formados por un miembro de la familia que no tiene escaño en la empresa familiar, pero sí en otra empresa de la sub-red, se indican en negro. Sin describir de manera exhaustiva las interconexiones entre las empresas, volvemos, para cada fecha, sobre las características principales de la sub-red, insistiendo sobre la dimensión familiar.

A comienzos de siglo, los vínculos todavía son poco densos, estando ademas aisladas nueve de las 22 empresas MEM (cf. figura 1). Tres sociedades familiares ocupan una posición central: Georg Fischer (ligada a 22 empresas), BBC (ligada a 12 empresas) y Von Roll (ligada a 9 empresas). BBC fue creada en 1891 por Charles E. L. Brown y Walter Boveri. Las innovaciones técnicas aportadas por los dos ingenieros (especialmente rotor cilíndrico y turbina a vapor) impulsan 
rápidamente a las empresas especializada en electrotecnia al primer rango de la industria suiza de máquinas: ya en 1901, cerca de la mitad de las máquinas eléctricas exportadas por el país son fabricadas por BBC (BBC 1966: 187). En 1910, más de la mitad de los escaños del consejo de administración, es decir seis sobre once, son ocupados por los miembros de las familias de los dos fundadores; algunos de ellos vinculados además a otras diversas empresas. En cuanto a Georg Fischer y Von Roll, son dirigidas por sus neo-fundadores, respectivamente Ernst Homberger y Johann Dübi. El primero fue llamado a dirigir la sociedad en cuanto los bancos poseedores de la mayoría de las acciones hubieron decidido apartar la familia fundadora en 1902. El segundo escaló progresivamente en el seno de las fábricas metalurgicas Von Roll durante 20 años, antes de acceder desde 1893 a la dirección de la empresa, y luego a su consejo de administración en 1920 en el que participó hasta su muerte en 1934. Ernst Homberger y Johann Dübi pueden ser considerados como neo-fundadores puesto que sus descendientes se encuentran en cada una de las dos sociedades: Hans Homberger, el hijo de Ernst, participa en el consejo de administración de Georg Fischer desde la muerte de su padre en 1955 y Ernst Dübi, hijo de Johann, quien entra en Von Roll en 1914, para ocupar más tarde el puesto de administrador-delegado en el cual se encuentra en 1937.

Aunque la mayor parte de los vínculos de la sub-red MEM recaen en miembros comunes entre los consejos de administración, se pueden identificar además cinco vínculos (en negro) puramente "familiares" creados por personas que no forman parte de aquellos consejos de la empresa controlada o dirigida por su familia, sino únicamente de una o varias de las otras 110 empresas. Es por ejemplo el caso de Werner Weber-Honegger, en el origen de los dos vínculos que unen Metallwaren Zug a MF Honegger; por una parte, y a Oerlikon-Bührle, por la otra. Metallwaren Zug no está ligada a ninguna de estas dos empresas por un administrador en común, pero es sin embargo controlada y dirigida por un miembro de la familia de Werner Weber-Honegger, puesto que el nieto del hermano del abuelo de éste ultimo, Oskar Weber-Künzli, es el presidente y administrador delegado. Werner Weber-Honegger es por su parte presidente del consejo de administración de Oerlikon-Bührle, y vice-presidente del consejo de MF Honegger, empresa fundada por el padre de su suegro, Caspar Honegger. 


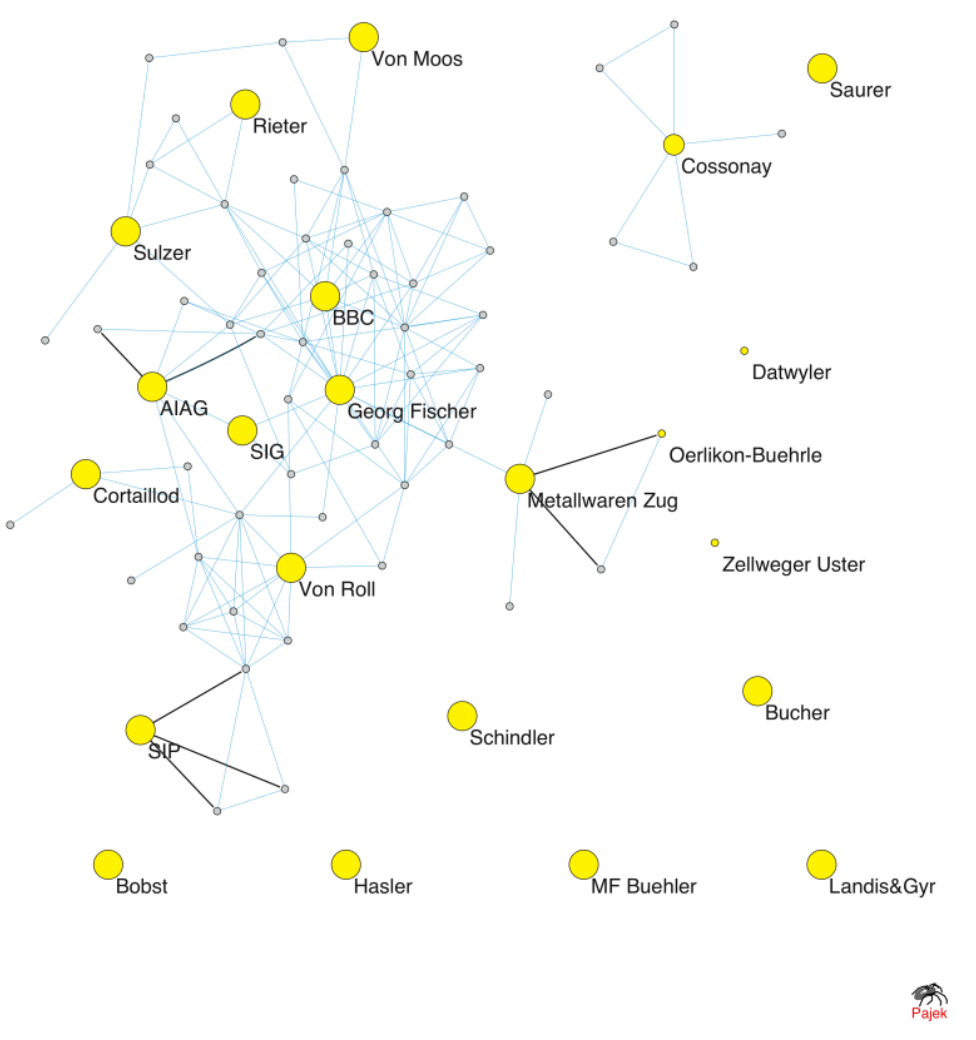

Figura 1. La sub-red de las 22 empresas MEM en 1910, vínculos cda y vínculos familiares.

Durante los tres decenios siguientes, las 22 empresas MEM continúan desarrollando vínculos entre ellas y con las 110 más grandes empresas suizas, haciendo la subred más densa y más cohesiva (cf. figura 2). Entre nuestras cinco fechas seleccionadas, es en 1937 cuando el capitalismo familiar es más fuerte en el seno de las 22 empresas MEM puesto que en ese año todas son controladas o dirigidas por una familia. BBC (25 vínculos) y Georg Fischer (22 vínculos) permanecen entre las empresas más centrales, con Sulzer (23 vínculos), fundada en nombre colectivo por Johann Jakob Sulzer y sus dos hijos Johann Jakob y Salomon en 1834, y transformada en sociedad anónima en 1914. La fuerte integración de las empresas familiares en la red se debe en parte a la vinculación de administradores exteriores a estas sociedades, pero también en los dirigentes familiares ejerciendo mandatos exteriores, contribuyendo así a tejer vínculos entre las empresas (ver igualmente la sección sobre los big linkers más abajo). Varios miembros de las familias a la cabeza de las 22 empresas ejercen además una o varias funciones únicamente en empresas diferentes a las pertenecientes a su familia. Se encuentra así especialmente a Emil-Huber-Stockar, hijo de uno de los fundadores de AIAG, en los consejos de administración de Zurich Assurance y de Motor-Columbus en 1937. Henri A. Naville-Muralt, hijo de Gustave Naville, otro cofundador de AIAG, preside por su parte el consejo de administración de BBC, y participa en los de la Báloise 
Assurance y la Sociedad financiera italo-suiza (SFIS). Juntos están en el origen de los vínculos "familiares" que unen AIAG a estas cinco empresas, que no cuentan con administradores en común con la sociedad metalúrgica.

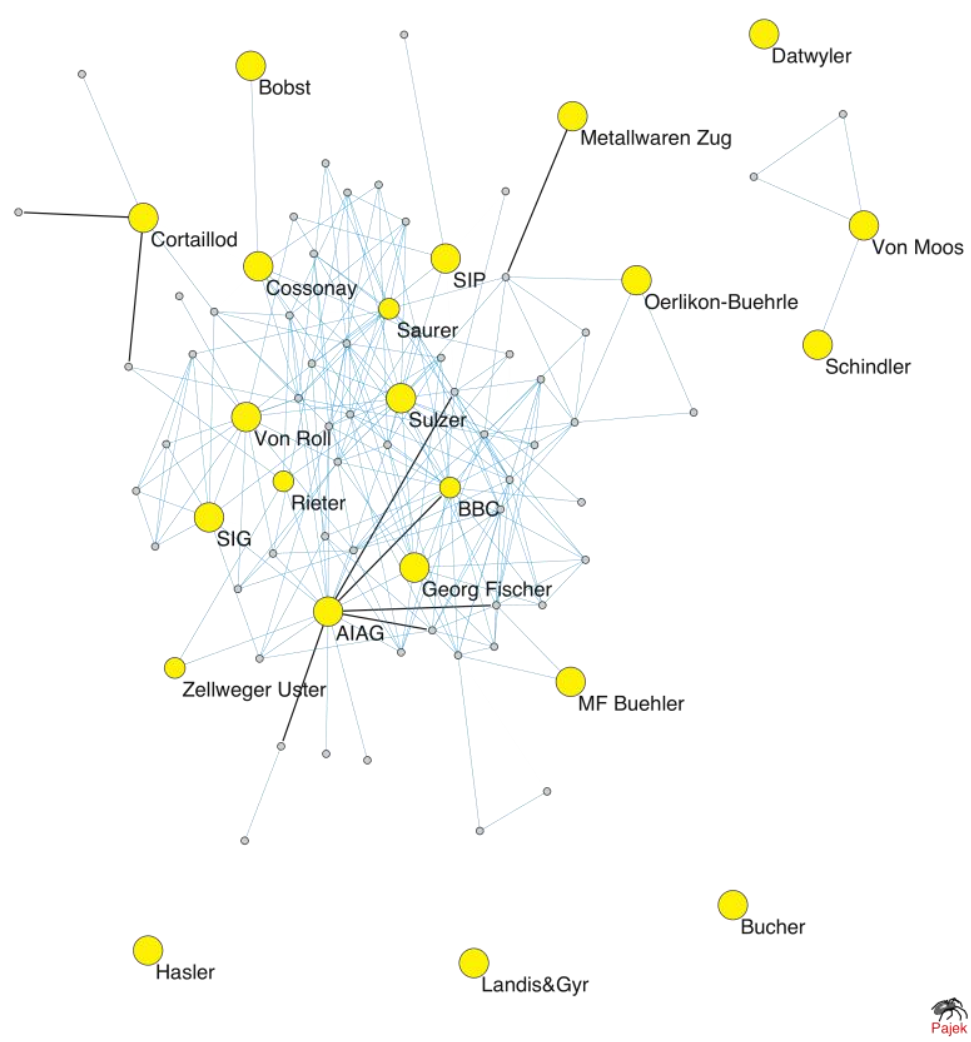

Figura 2. La sub-red de las 22 empresas MEM en 1937, vínculos cda y vínculos familiares.

La fuerte persistencia del capitalismo familiar, por una parte, y la consolidación de las interconexiones entre los consejos de administración de las grandes empresas, por la otra, en el curso de la primera mitad del siglo XX, están bien ilustradas por la sub-red de 1957 (cf. figura 3). Con 31 vínculos, Sulzer ocupa la posición central: su consejo de administración está compuesto por 19 personas, que ejercen en total 84 mandatos en las 110 empresas más grandes en aquel año; esto es, en promedio 4,4 mandatos por persona. Siete administradores forman parte de la familia fundadora, hay dos por alianza. Opuestamente, sólo Dätwyler y Bucher no comparten miembro alguno con algunas de las 110 empresas suizas más grandes durante todo este periodo. La primera representa un caso particularmente interesante, puesto que es relativamente atípico en comparación con las otras sociedades MEM. Fundada en 1902 por un grupo de intereses alemán, esta manufactura de cables y de caucho pertenece desde principios de los años 1910 a la Caja de Ahorro de Uri. Esta última pone en 1914 a Adolf Dätwyler en la dirección 
de la empresa, mientras atraviesa una grave crisis financiera. Llega poco a poco a redirigir el asunto, y a adquirir en 1917 las acciones pertenecientes al cantón, garante de la Caja de Ahorro que ha entrado también en quiebra. Adolf Dätwyler puede ser considerado como un self-made man: no cuenta con una fortuna, su padre es agricultor y sastre. Su carrera en la empresa, que dará fama a su nombre en 1946, es el origen de su ascensión social y, a partir de allí, la de su familia: se casa en 1924 con Selina Gamma, hija de Martin Gamma, quien es el landammann ${ }^{14}$ que ha obtenido un préstamo de la Confederación durante la quiebra de la Caja de Ahorros (Dätwyler 1965). A la muerte de Adolf en 1958, sus dos hijos, Max y Peter, retoman la dirección de la empresa, que desarrollan a nivel internacional, y que permanece en manos de la familia hasta los años 1990. El recorrido atípico de Adolf, quien no pertenece originalmente a las grandes familias helvéticas, constituye una hipótesis para explicar la integración tardía de su sociedad en la red: en 1957, el consejo de administración sólo está en efecto compuesto por miembros de la familia Dätwyler. Por ultimo, solamente Metallwaren Zug y MF Honegger permanecen unidos por un vínculo puramente familiar en ese año: Gerold Weber, hijo de Werner Weber-Honegger (cf. más arriba), participa en efecto en el consejo de administración de la segunda sociedad.

14 Término helvético para designar al presidente del gobierno de ciertos cantones campesinos, de los cuales Uri forma parte. 


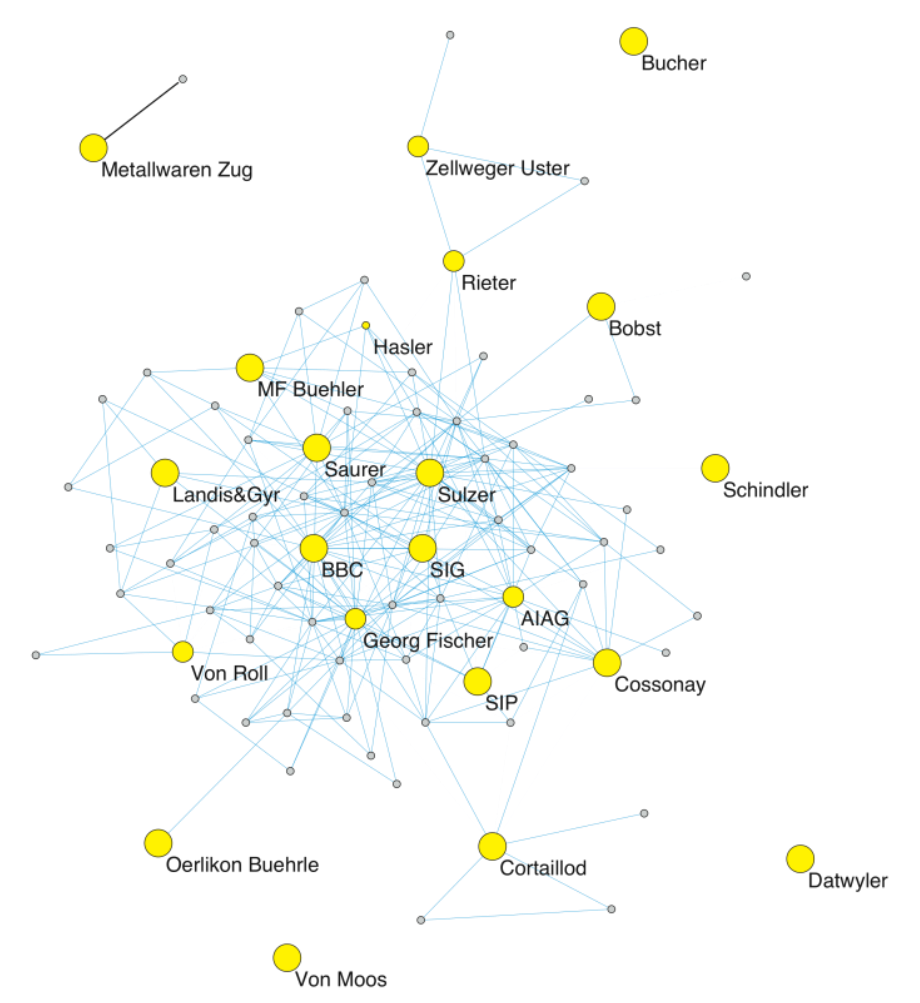

Figura 3. La sub-red MEM en 1957, vínculos cda y vínculos familiares.

Le sub-red MEM continúa densificándose y haciéndose más cohesiva hasta principios de los años 1980, que representan, entre las cinco fechas seleccionadas, el único periodo en que todas las empresas MEM estan conectadas a la red de las 110 más grandes empresas suizas. Aunque se observa una fuerte persistencia del capitalismo familiar, ocho de las 22 empresas no están ya controladas o dirigidas por una familia. En varios casos, las familias dirigentes han sido excluidas por los bancos comprometidos en estas empresas durante periodos de crisis. Por ejemplo, en 1966, los bancos implicados con la empresa BBC, que detenta entonces la mayoría de los derechos de voto, ponen en cuestión la capacidad del hijo de uno de los fundadores, Walter E. Boveri, ya envejecido, para manejar la presidencia del consejo de administración que ocupa desde 1938, apoyando así colectivamente la nominación de un miembro exterior a la familia en su lugar (Catrina 1991). Los bancos proceden igualmente a numerosas reestructuraciones en el periodo de crisis que sigue al choque petrolero de 1973, marcado por la sobreproducción mundial y, en Suiza, por un Franco fuerte que contribuye a debilitar las exportaciones de la industria MEM (Widmer 2009: 274). En otros casos de figura, la desaparición de la familia fundadora resulta simplemente de la ausencia de descendientes que retomen los negocios: es así que la dinastía fundadora desaparece de la empresa Rieter cuando Benno Rieter, único representante de la quinta generación, muere sin 
dejar descendencia. El capitalismo familiar permanece aún, no obstante, como el modo de gobernanza dominante a inicios de los años 1980: en total, 14 de las 22 empresas seleccionadas pueden ser consideradas como una empresa familiar en 1980, según nuestra definición. En efecto, varias familias han podido adoptar ciertas estrategias permitiéndoles mantener la posesión de su sociedad entre sus manos. Los Schindler, por ejemplo, han implementado un contrato de accionistas, con el fín de que las acciones nominativas queden dentro de la familia, estando el capital de su sociedad, como el de muchas empresas helvéticas durante la mayor parte del siglo, estructurado sobre la base de varias categorías de acciones. ${ }^{15}$ La empresa, fundada en 1874 por Robert Schindler, se convierte así en una multinacional líder en el dominio de los ascensores électricos y de las escaleras mecánicas, permaneciendo en manos de la misma dinastía fundadora: en 1980, es clasificada en el $13^{\circ}$ lugar de las más grandes empresas industriales de Suiza según el criterio de volumen de ventas (UBS 1980). Ademas, ésta se integra progresivamente en la red de las 110 más grandes empresas helvéticas. Hasta el final de los años 1950, la sociedad permanece muy cerrada: círculo restringido de administradores, no publicación de informes anuales, pocos vínculos de interconnexión con las otras empresas. En 1980, el consejo de administración cuenta con 10 personas, y la sociedad está ligada a otras 15 empresas, por la vía de administradores exteriores, pero igualmente por intermedio de los miembros de la familia fundadora quienes cuentan ahora también con escaños en otras sociedades.

La sub-red MEM de 1980 (cf. figura 4) ilustra bien este estado transitorio, caracterizado a la vez por la persistencia y el debilitamiento relativo del capitalismo familiar. Por vez primera, las dos empresas más centrales en la red no son controladas o poseídas por una familia (BBC, 32 vínculos y Alusuisse, 27 vínculos); éstas son sin embargo seguidas por Sulzer en tercera posición (23 vínculos), que queda por su parte en manos de la dinastía fundadora. Se observa además una disminución de los vínculos puramente "familiares": sólo Urs Bühler, bisnieto del fundador de la empresa MF Bühler, no cuenta este año con un escaño en la empresa familiar (entra en 1981 al consejo de administración), pero ocupa un

15 En 1980, el capital de la sociedad comporta acciones nominativas de valor nominal de $100 \mathrm{CHF}$ y de acciones al portador de valor nominal de $500 \mathrm{CHF}$ : Además dice, el derecho de voto cuesta cinco veces más caro para un propietario de una acción al portador que por aquel en posesión de una acción nominativa. 
mandato en la SBS, lo que viene así a reforzar por una relación familiar, el vínculo existente por un administrador común entre las dos sociedades.

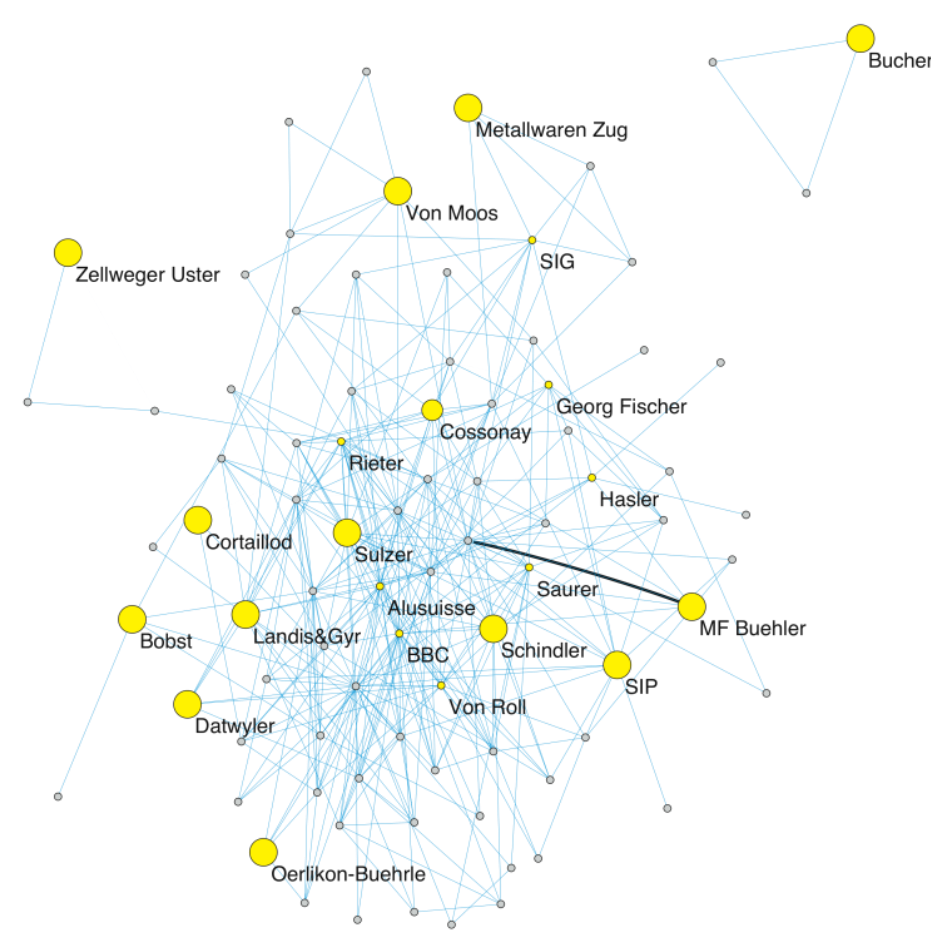

Figura 4. La sub-red de las 22 empresas MEM en 1980, vínculos cda y vínculos familiares.

\section{¿Del capitalismo familiar al capitalismo financiero?}

La evolución de la sub-red MEM en el curso de los dos últimos decenios del siglo está marcada por un fuerte declive de las interconexiones entre empresas, claramente visible en la estructura de la red en 2000 (cf. figura 5). Mientras que en promedio, cada empresa estaba ligada a aproximadamente otras ocho sociedades en 1957 y en 1980, el número promedio de conexiones disminuye a la mitad al final del siglo (cf. tabla 1 mas arriba). Para Schnyder et al. (2005), la decadencia de las interconexiones igualmente observada en este periodo en los consejos de administración de las 110 más grandes empresas suizas se explica principalmente por una transformacion profunda de la gobernanza de empresa en Suiza, desde ahora más centrada en el valor accionista, en un contexto de globalización creciente de la economía (ver igualmente David et al. 2011 por publicar y Schnyder 2007). En efecto, desde la segunda mitad de los años 1980 y bajo la presión creciente de los mercados financieros y de los inversionistas institucionales, el derecho de las SA en Suiza sufre varias reformas y, como en otros países europeos, las empresas helvéticas comienzan a poner en práctica estrategias que 
respondieran mejor a los criterios de transparencia, y que buscaran satisfacer los intereses de los accionistas minoritarios (David et al. 2011 por publicarse: [292]). Un cierto número de éstas renuncian así, entre otros ejemplos, a recurrir a la distorsión de los derechos de voto, o a la emisión de diferentes categorías de acción. Estos cambios han contribuido a la decadencia de la red de dos maneras. Por una parte, los promotores del valor accionista han reclamado una disminución del tamano del consejo de administración, considerado más eficaz; por otra parte, se mobilizaron en favor de una profesionalizacion de la función de administrador, haciendo por consecuencia más dificil el cúmulo de mandatos (Schnyder et al. 2005: 48-49). Estos cambios han sido especialmente promovidos por una nueva categoría de actores financieros helvéticos, los "raiders", cuyo propósito consiste en adquirir una participación suficiente en una empresa para poder influenciar la estrategia en el sentido de una mejor distribución de beneficios en favor de los accionistas. Finalmente, los mecanismos tradicionales de cooperación entre las élites suizas han sido fuertemente cuestionados al final del siglo. Estas transformaciones globales han afectado igualmente al sector de la metalurgia: Widmer (2009) muestra en efecto que al final de los años 1990, los inversionistas institucionales (en particular los fondos de inversión) toman importantes participaciones en las sociedades MEM. Así, se observa efectivamente una disminución del tamaño promedio del consejo de administración de las empresas de nuestra muestra, puesto que pasa de nueve miembros en promedio en 1980, a 7,9 miembros en 2000, y se constata igualmente una disminución del cúmulo de mandatos (cf. tablas 1 y 2 más arriba). Aunque estos diferentes factores han contribuído a la decadencia general de los interlocks entre las grandes empresas a finales del siglo, el caso de máquinas y metales nos lleva no obstante a matizar esta constatación: se comprueba en efecto un mantenimiento significativo de los vínculos en el seno mismo del sector MEM (ver igualmente la siguiente sección), haciendo por consiguiente la estructura de la sub-red en 2000 muy diferente de aquella de 1910. El número global promedio de vínculos es ligeramente más débil al final del siglo que al inicio, pero a pesar de todo la red en conjunto queda relativamente conexa: en particular, hay sólo una empresa aislada en 2000 (Saurer), contra nueve en 1910.

La figura 5 hace igualmente aparecer la erosión del capitalismo familiar en el seno del sector MEM. Para Widmer, es el advenimiento del capitalismo financiero lo que permite explicar esta evolución: según éste, «la figura del propietario histórico, especialmente las familias fundadoras que bloquean el acceso al control de la empresa, han desaparecido ampliamente de la gobernaza de empresa de las 
mayores sociedades MEM » con el incremento de los inversionistas institucionales y el crecimiento de la capitalización bursatil de las empresas (2009: 220). Nuestros resultados nos llevan sin embargo a matizar fuertemente esta constatación, puesto que, en total, nueve de las 18 empresas tomadas en cuenta para el año 2000 son aún empresas familiares. Estos resultados muestran que si bien el capitalismo familiar decae con respecto a la primera mitad del siglo, éste es, no obstante, significativo en 2000. Las empresas familiares que subsisten están todavía bien integradas en la red por la vía de miembros comunes entre los consejos de administración; ya no se observan, por el contrario, vínculos puramente familiares.

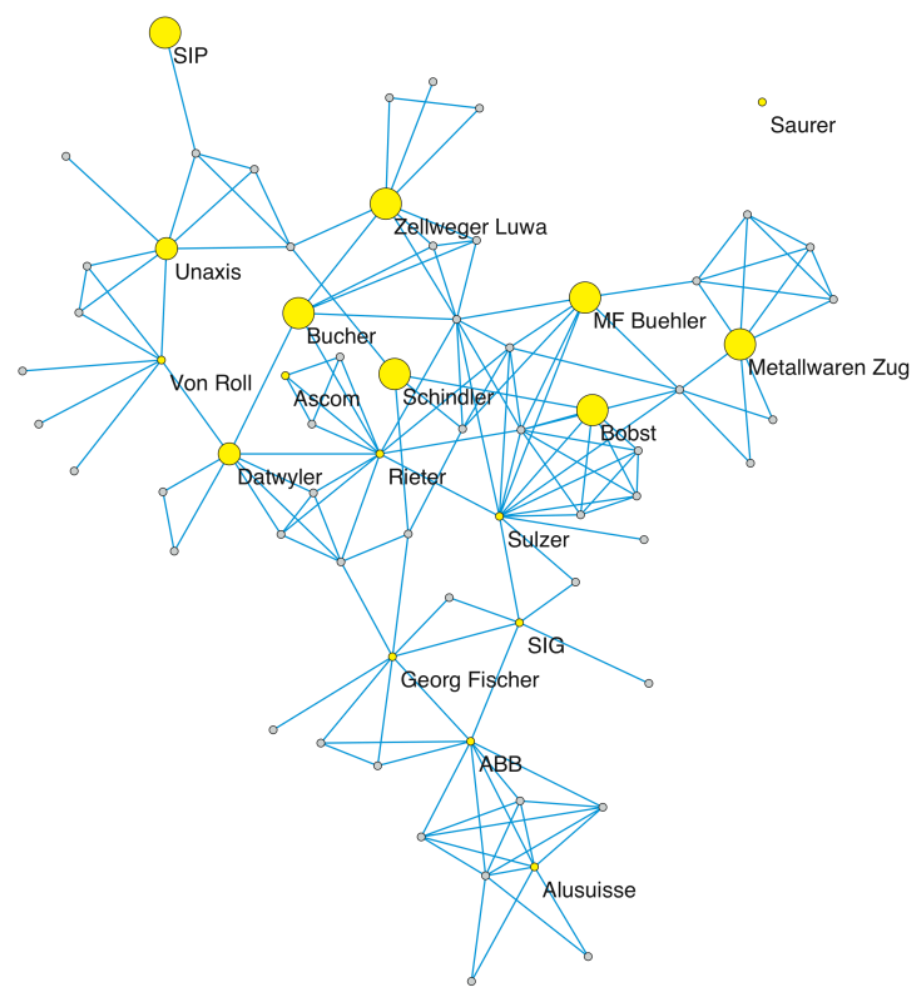

Figura 5. La sub-red de empresas MEM en 2000, vínculos cda de Big linkers y cohesión de las élites.

La tabla 2 presentada anteriormente muestra la presencia significativa, en el curso del siglo, de big linkers que acumulan al menos tres mandatos en la sub-red MEM: entre $18 \%$ y $30 \%$ según el año considerado. Sus mandatos están esencialmente concentrados en el sector de la metalurgia y, hasta los años 1980, en el sector bancario. Durante más de la primera mitad del periodo, los dirigentes familiares de las 22 empresas MEM de nuestra muestra, representan además más de un cuarto de los big linkers (cf. tabla 3). 


\begin{tabular}{|c|c|c|c|c|c|}
\hline & 1910 & 1937 & 1957 & 1980 & 2000 \\
\hline $\begin{array}{l}\text { Numero de big } \\
\text { linkers }(B L)\end{array}$ & 24 & 39 & 46 & 53 & 24 \\
\hline $\begin{array}{l}\text { Mandatos en las } 110 \\
\text { empresas suizas más } \\
\text { grandes }\end{array}$ & 115 & 164 & 192 & 225 & 93 \\
\hline \multicolumn{6}{|l|}{ De las cuales: } \\
\hline bancos & $30,0 \%$ & $28,0 \%$ & $23,4 \%$ & $20,4 \%$ & $11,8 \%$ \\
\hline empresas MEM & $32,2 \%$ & $44,5 \%$ & $45,8 \%$ & $44,4 \%$ & $50,5 \%$ \\
\hline $\begin{array}{l}\text { Numero de BL } \\
\text { familiares }\end{array}$ & $9 / 24$ & $11 / 39$ & $13 / 46$ & $4 / 53$ & $2 / 24$ \\
\hline $\begin{array}{l}\text { Mandatos en las } 110 \\
\text { empresas suizas más } \\
\text { grandes }\end{array}$ & 35 & 43 & 53 & 17 & 8 \\
\hline \multicolumn{6}{|l|}{ De las cuales: } \\
\hline bancos & $28,6 \%$ & $16,3 \%$ & $20,7 \%$ & $23,5 \%$ & $12,5 \%$ \\
\hline empresas MEM & $51,8 \%$ & $60,0 \%$ & $58,5 \%$ & $47,0 \%$ & $50,0 \%$ \\
\hline
\end{tabular}

Tabla 3. Repartición de mandatos de los big linkers en las 110 empresas más grandes.

La tabla 4 nos permite además concluir que estos big linkers representan un grupo de actores particularmente conexo, puesto que están casi todos ligados a un componente principal durante todo el periodo considerado.

\begin{tabular}{|l|c|c|c|c|c|}
\cline { 2 - 6 } \multicolumn{1}{c|}{} & $\mathbf{1 9 1 0}$ & $\mathbf{1 9 3 7}$ & $\mathbf{1 9 5 7}$ & $\mathbf{1 9 8 0}$ & $\mathbf{2 0 0 0}$ \\
\hline $\begin{array}{l}\text { BL incluidos en el } \\
\text { componente principal }\end{array}$ & 22 & 38 & 46 & 51 & 22 \\
\hline $\begin{array}{l}\text { BL excluidos del } \\
\text { componente principal }\end{array}$ & 2 & 1 & - & 2 & 2 \\
\hline
\end{tabular}

Tabla 4. Cohesion de los big linkers en el seno de la sub-red MEM.

La presencia significativa de dirigentes familiares entre los big linkers muestra que las fuertes conexiones entre las empresas familiares y el resto de la red no se apoyan unicamente sobre directores externos. Así, por ejemplo, Hans Sulzer acumula en 1937 siete funciones en las 110 más grandes empresas suizas, entre las cuales están especialmente, la presidencia del consejo de administración de la sociedad Sulzer, fundada por su abuelo, la del consejo de la Winterthour Assurance, la vice-presidencia de la empresa metalúrgica Maag y un mandato como miembro el consejo de UBS. En 1980, su hijo Georg Sulzer-Schwarzenbach preside los consejos de administración de Sulzer y de Maag, y participa en los consejos de 
Winterthour Assurance y de UBS. Estos ejemplos dan testimonio de la gran diversidad de los mandatos ejercidos por los dirigentes familiares, no se reducen en absoluto al sector MEM. Muestran además que la transmisión de funciones de poder entre miembros de una misma dinastía no se limita a la empresa familiar, sino que se extiende a veces igualmente a las funciones ocupadas en otras sociedades. La proyección de los vínculos familiares en la red interempresas puede igualmente ser identificada por la vía de las alianzas en una misma generación, como lo ilustra el ejemplo de Robert de Pury. Nacido en 1868 en Neuchátel, es el hijo del banquero Edouard de Pury y de Louise Marie Wavre. Adquiere una formación en el sector bancario, y se casa en 1893 con Suzanne de Coulon, descendiente de una de las familias fundadoras de la empresa Cortaillod. Desde 1897, o sea cuatro años después de su matrimonio, participa en el consejo de administración de Cortaillod, hasta 1925. En 1910, forma parte de los consejos de administración de dos sociedades financieras, Anlagewerte y Metallwerte. La tabla 3 muestra además que los dirigentes familiares ocupan un número significativo de escaños en los bancos. Dicho de otra forma, las conexiones múltiples que unen las empresas familiares a los bancos durante la mayor parte de siglo (ver la sección siguiente) no se explican únicamente por el hecho de que los banqueros participasen en estas empresas. La presencia recíproca de los dirigentes familiares en los bancos nos permite entonces matizar la hipótesis de un control formal por los bancos (bank control model). Finalmente, el hecho de que los big linkers constituyan un grupo fuertemente cohesivo (cf. tabla 4 arriba) nos incita igualmente a relativizar la idea de un control ejercido por la familia (family control model), y a confirmar la hipótesis de una coordinación entre las élites económicas en el sentido del modelo de cohesión de clase.

\section{Coordinación y control: la red 2-slices}

Esta segunda parte del análisis se concentra, a partir de las redes presentadas en la primera parte de la investigación, sobre los vínculos fuertes entre las firmas, con el fin de profundizar la cuestión de los mecanismos de cooperación. Las figuras 6 a 10 presentadas en adelante se enfocan así sobre las sociedades que comparten al menos dos miembros en común (2-slices). De la misma manera que en las figuras 1 a 5, las empresas MEM que forman parte del grupo de partida de 22 están indicadas en amarillo, y su tamaño es proporcional al grado de capitalismo familiar mediante un vector. Las otras sociedades MEM que aparecen en la sub-red, puesto que pertenecen en una $u$ otra fecha a las 110 firmas suizas más grandes, pero no forman parte de las 22 firmas de partida, no existen durante todo el siglo, están indicadas en naranja. Los bancos y las sociedades financieras están señalados en 
azul, y las empresas de los otros sectores (textil, seguros, construcción, transportes...) en gris.

\section{Alianzas regionales e interconexiones con el sector bancario}

En 1910, sólo cinco sociedades MEM entre las 22 que nos interesan están ligadas entre ellas o a otra firma pertenecientes a la red de las 110 empresas suizas más grandes por un vínculo multiple: AIAG, BBC, Georg Fischer, Rieter et SIG. Estas empresas forman ya parte de las 110 firmas más grandes y disponen además de un consejo de administración bastante amplio, lo que explica su integración más precoz y más fuerte en la red. En esta época las conexiones se establecen, por una parte, esencialmente sobre una base regional, y por otra parte, con el sector bancario y financiero. A nivel geográfico, los vínculos están, en efecto, concentrados en los cantones alemanes situados al norte del país, y en particular alrededor de tres grandes ciudades, a saber, Zürich, centro financiero e industrial y Schaffhouse y Winterthour, cunas de la industria de máquinas. Así, por ejemplo, la fundidora Georg Fischer, creada por Johann Conrad Fischer en Schaffhouse en 1802, conectada con una hilatura de la misma ciudad (Spinnerei Schaffhausen) y Rieter, empresa fundada por Johann Jacob Rieter en Winterthour al final del siglo XVIII, productora especialmente de máquinas de hilar y de tejer, está conectada a una industria de seda igualmente establecida en Winterthour (Winterthur Seiden); finalmente, SIG y Georg Fischer estan aún ligadas a SLM, asimismo ubicada en Winterthour.

A nivel sectorial, los vínculos establecidos por las empresas MEM al inicio de siglo se apoyan sobre todo en el sector bancario y financiero, y en particular en sociedades financieras especializadas: Elektrobank, Motor-Columbus y Metallwerte. Creadas en su mayor parte al final del siglo XIX para financiar las empresas industriales $y$, en particular, las del sector eléctrico que requiere de grandes inversiones, estas sociedades financieras representan un tipo particular de holding: "al contrario del caso de los fondos de inversión, estas se caracterizaban por sus intereses controladores en empresas que operaban en la misma industria"16 (Paquier 2001: 164). Así, Elektrobank es fundada en 1895 para poner créditos a disposición de las empresas de electricidad, tal como lo indica su nombre. El mismo año, Motor $\mathrm{AG}^{17}$

\footnotetext{
16 "Unlike investment trusts, these were characterised by their controlling interests in firms that all operated within the same industry"
}

17 Se vuelve Motor-Columbus en 1923, tras su fusión con Columbus AG. 
es creada para financiar las instalaciones eléctricas de BBC, a la cual está muy fuertemente ligada en 1910: las dos sociedades comparten en efecto seis miembros en común (el consejo de administración de Motor AG compuesto por 13 personas, y el de BBC por 11 administradores) y Walter Boveri-Baumann (co-fundador de BBC) ocupa la presidencia del consejo de administración de la sociedad financiera.

Aunque las conexiones con el sector bancario predominan muy claramente a principios de siglo, las empresas MEM han establecido igualmente algunos vínculos con empresas industriales. Así, los interlocks mencionados anteriormente entre Georg Fischer y Spinnerei Schaffhausen, y Rieter y Winterthour Seiden, se explican por una parte por el factor geográfico, pero por otra parte por el hecho de que la industria de máquinas se desarrolló en el siglo XIX a partir de la mecanización del sector textil. En 1910 existen algunas conexiones igualmente entre las firmas MEM mismas, cuyas actividades son en algunos casos muy cercanas: SIG está ligada por dos miembros a SLM -la primera fabrica wagons a inicios de siglo, mientras que la segunda produce por su parte locomotoras a vapor y elementos mecánicos para locomotoras eléctricas. Otro ejemplo es el de la fábrica de material eléctrico Alioth, fundada en Bále en 1881 por Ludwig Rudolf Alioth y Emil Bürgin: en 1910, tres miembros de las familias fundadoras de BBC (Walter Boveri-Baumann, Sydney William Brown-Sulzer y Fritz Funk), industria destacada de la electrotecnia, participan en el consejo de administración de Alioth. Sin embargo, los vínculos intrasectoriales se desarrollan de manera significativa durante los decenios siguientes. 


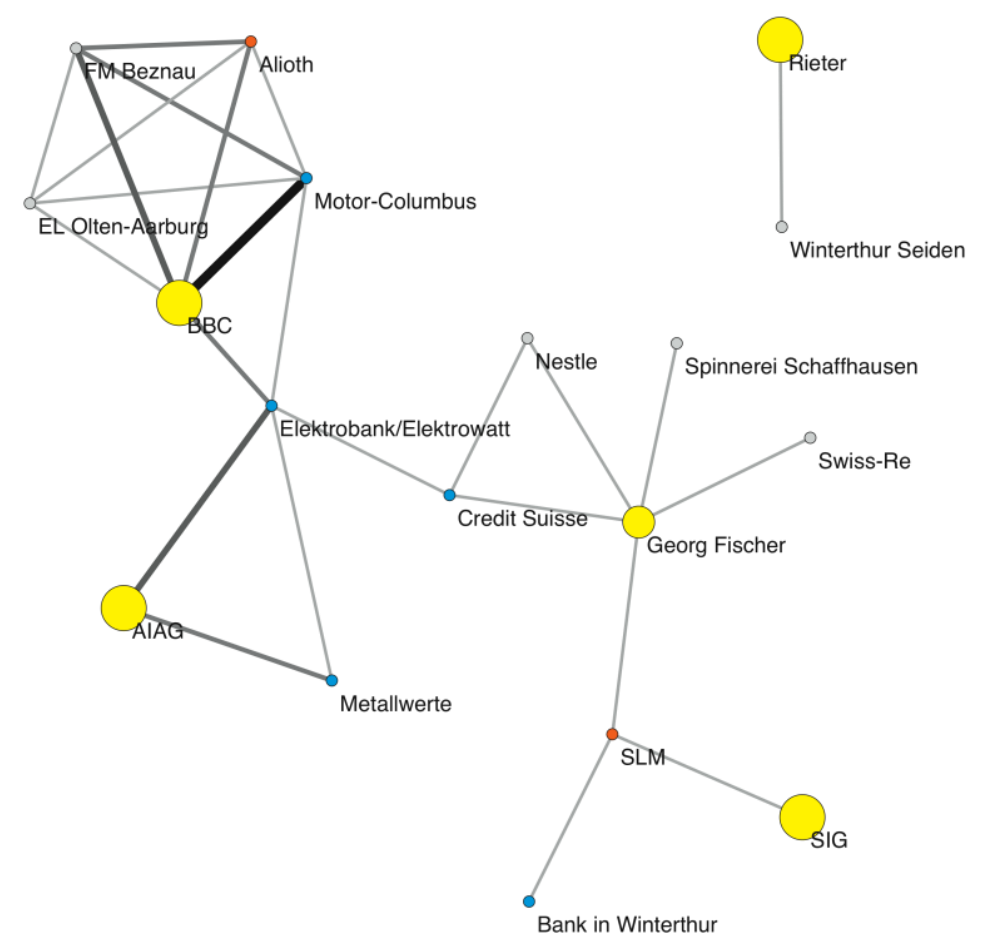

Figura 6. La sub-red de las 22 empresas MEM en 1910, 2-slices.

La situación de 1910 precede a la constitución de la red nacional. El número d'interlocks entre las firmas es relativamente débil con respecto a los decenios siguientes, puesto que las empresas industriales y las sociedades financieras helvéticas están aún fuertemente volcadas hacia el exterior, y en particular hacia Alemania. Pero la Primera Guerra mundial viene a transformar la situación de forma duradera: « en los años que siguieron la Primera Guerra Mundial la economía suiza se volvió más integrada internamente y al mismo tiempo crecientemente independiente de la influencia externa $\gg^{18}$ (Schnyder et al. 2005 : 26). Por una parte, la derrota alemana y el marasmo económico que le sigue al país genera un debilitamiento de los vínculos económicos entre Suiza y Alemania, aun si éstos siguen siendo estrechos. Pero la creciente independencia de la esfera económica suiza implica también, por otro lado, una voluntad por parte de las élites de liberarse de la influencia exterior, como lo demuestra la medida destinada a limitar el número de administradores extranjeros asignados al derecho de las sociedades

\footnotetext{
18 « in the years following the First World War the Swiss economy became more fully integrated internally and at the same time increasingly independent from external influence »
} 
de 1919, una medida inmersa en el contexto del aumento extenso de la xenofobia en Suiza (Lüpold 2008: 209).

\section{Desarrollo de los vínculos intra-sectoriales}

Durante los decenios posteriores a la finalización de la Primera Guerra, la sub-red de los vínculos fuertes se vuelve más conexa y más fuerte, y el sistema de coordinación entre las empresas por la vía de los interlocks se refuerza, integrando desde entonces empresas de la parte francófona del país: Cossonay (VD), Cortaillod (NE), SIP (GE) y Sécheron (GE). Aunque la sub-red se extiende entonces sobre una superficie geográfica más amplia, se constata no obstante cierta persistencia de las alianzas formadas sobre una base regional: así, las empresas de la parte francófona del país están directamente ligadas entre ellas (Cossonay y Cortaillod por una parte; SIP y Sécheron, por la otra), Georg Fischer está interconectada a SIG (Schaffhouse), Sulzer a la Winterthur Assurance (Winterthour), y Von Roll a Scintilla (Soleure). El desarrollo de la sub-red resulta en gran parte de las crecientes interconexiones con el sector bancario y financiero: en adelante, los tres grandes bancos suizos (SBS, UBS y CS) ocupan en efecto una posición central en la red, bajo el mismo título que las sociedades financieras. La figura 7 (cf. infra) muestra además claramente que las instituciones bancarias y financieras juegan un fuerte rol de intermediarios en la sub-red MEM: muchas empresas son, en efecto, puestas de nuevo en relación entre ellas por la vía de una de estas instituciones. Se observa sin embargo, en paralelo, el desarrollo significativo de interconexiones entre las firmas MEM mismas, más fuertes y más numerosas que con otros sectores industriales. En ciertos casos, estos vínculos existen entre sociedades que realizan actividades complementarias: SIG, por ejemplo, fabrica armas desde 1860, mientras que Georg Fischer se lanza en 1936 en la producción de municiones; Von Roll se especializa en la producción de hierro para la industria automotriz, y Scintilla en la de los motores de combustión interna; Sulzer fabrica, entre otros, motores diesel, mientras que Saurer produce, además de máquinas-herramientas para el sector textil, camiones y vehículos utilitarios. Se puede así suponer que los interlocks entre estas empresas se sitúan en el marco de una relación entre clientes y proveedores, aunque esta hipótesis deba aún ser confirmada por elementos empíricos.

En otros casos, los vínculos intra-sectoriales se sitúan entre firmas que ejercen actividades similares, y muestran muy claramente un proceso de coordinación entre estas sociedades, pudiendo ir de la simple cooperación a una forma de control que pasa por una participación. Típicamente es el caso entre Cortaillod y Cossonay. 
Activa en el dominio de cables eléctricos, Cortaillod fue creada en 1884 por François Borel, Edouard Berthoud y Robert de Coulon, bajo la forma de una sociedad anónima. Las Fábricas de cables y Fábricas de alambres de Cossonay han sido por su parte fundadas algunos años más tarde, en 1898, por Jean-Marcel Aubert. Desde 1912, un cártel suizo funciona entre estas dos empresas así como una tercera fábrica de alambres, Suhner \& Cie (que no forma parte de las 110 empresas suizas más grandes), comunicándose entre las tres toda solicitud de precio de cierta importancia y negociando los lotes de pedido o la fijación de precios, sin firmar un acuerdo formal en un primer momento (Cortat 2009: 214). En 1923, Cortaillod adquiere una participación mayoritaria en Cossonay, y se encuentra de nuevo desde ese año a miembros del consejo de administración de la primera, y en particular descendientes de una de las dinastías fundadoras, la familia de Coulon, en aquel de la segunda (las dos sociedades estan así ligadas por tres miembros comunes en 1937 y en 1957, cf. figuras 7 y 8). En 1928, a fin de poder afiliarse al cártel internacional de cables recientemente creado, las tres fábricas firman una convención estableciendo un cupo de mercado y la fijación de precios, instaurando así un cártel en Suiza (Cortat 2009: 217).

Varios autores han puesto en evidencia la existencia de un vínculo directo entre "cartelización" y redes de interconexión. Windolf (2009) ha mostrado por ejemplo que en el caso de Alemania, la red de empresas se densifica tras la Primera Guerra mundial, al mismo tiempo que el grado de "cartelización" aumenta; por el contrario, en los Estados Unidos, la red se vuelve menos densa con el refuerzo de leyes anti-trust y el desarrollo de un capitalismo competitivo (ver igualmente Mizruchi 1996: 273-274). Aunque esta cuestión se aleje del propósito que nos interesa y no pueda ser objeto de un análisis en profundidad en el marco de esta contribución, es interesante recordar que, como en el caso de Alemania, Suiza conoció un fuerte proceso de cartelización desde el periodo entre guerras (ver especialmente Schröter 1999 y Cortat 2010). La industria metalúrgica y electrotécnica, entre otras, ve la creación de numerosos cárteles, y firmas como BBC, AIAG y Georg Fischer participan en cárteles nacionales e internacionales (Schröter 1999: 191-192). Los conocimientos sobre la cuestión permanecen no obstante muy incompletos actualmente -los datos relativos al número de acuerdos creados durante la segunda mitad del siglo $\mathrm{XX}$, en particular, permanecen aun sin conocerse- y la hipótesis de un vínculo directo entre interlocks y acuerdos de cártel para la industria suiza queda por confirmar. Podemos aventurarnos a afirmar que los vínculos de interconexiones entre las firmas y los cárteles han aumentado de manera paralela, y que tanto los primeros como los segundos representan una de 
las expresiones del capitalismo cooperativo que caracteriza la economía helvética durante la primera mitad del siglo, hallándose las empresas familiares junto a los grandes bancos, en el centro de este sistema, como bien lo ilustra la sub-red del sector MEM en 1937 y en 1957 (cf. figuras 7 et 8 abajo).

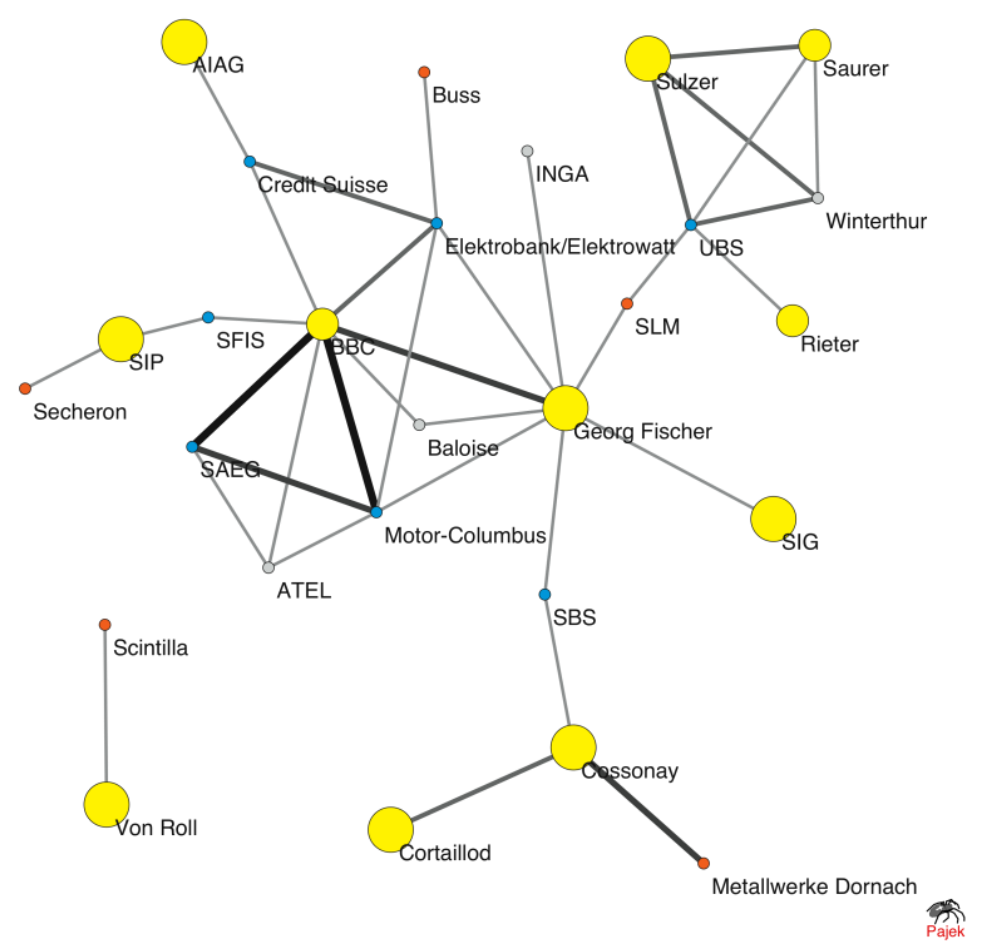

Figura 7. La sub-red de las 22 empresas MEM en 1937, 2-slices.

La consolidación de la sub-red MEM se realiza en el contexto del fuerte desarrollo de este sector, que representa antes del segundo conflicto mundial la principal rama industrial del país en términos de exportaciones y de mano de obra empleada (Billeter 1985). Si bien los interlocks de las empresas MEM continuan desarrollándose con bancos y sociedades financieras hasta los años 1980, el número de interconexiones confinadas en el seno del sector MEM predomina después de los años 1930 (cf. tabla 5 infra). Aunque no sea posible explicar de manera sistemática la significación de estos vínculos, se puede no obstante identificar cierto número de casos en que éstos requieren un mecanismo de cooperación entre las firmas. Varios ejemplos, además de los mencionados precedentemente, comprueban en efecto un proceso de cooperación entre los dirigentes de firmas activas en sectores similares en el curso de este periodo. Así, en 1940, los dirigentes de Von Roll, Von Moos, Sulzer y Georg Fischer deciden crear un consorcio para la fusión de minerales de hierro suizos, con el propósito de promover la producción nacional de hierro. Ahora bien, en 1937, E. Dübi, 
administrador-delegado de Von Roll, dispone de un escaño en el consejo de administración de Sulzer, ligada a Georg Fischer por un administrador común, Max Staehlin. En 1957, Sulzer está aún ligada a Georg Fischer por dos administradores comunes (cf. figura 8). En este periodo del siglo, la sub-red MEM se hace particularmente cohesiva, puesto que más de la mitad de las 22 firmas MEM están integradas en la red 2-slices, por una parte, y por la otra, ésta última está constituida por un componente principal muy cohesivo, en el que no están integrados dos componentes (Pars Finanz y Schindler, y Bobst y ACMV).

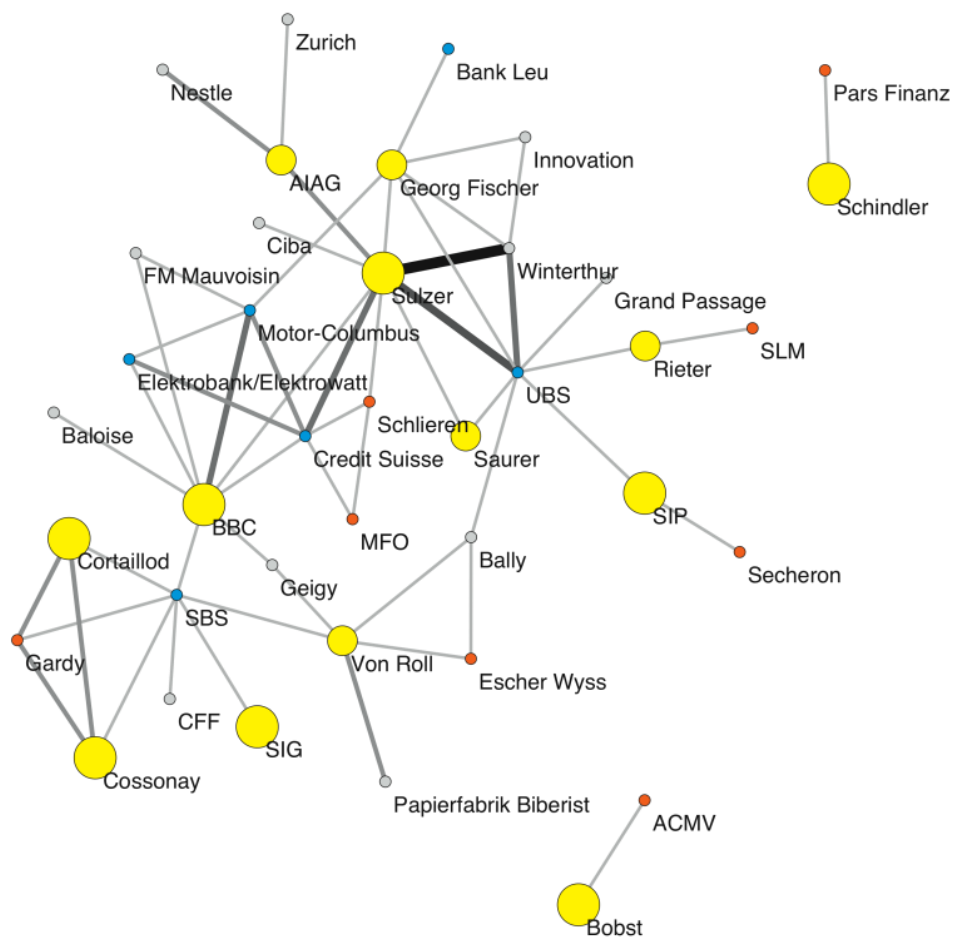

Figura 8. La sub-red de las 22 empresas MEM en 1957, 2-slices.

Durante los dos decenios siguientes, la cohesión de la sub-red MEM se refuerza: en 1980, 15 firmas sostienen al menos un vínculo doble con otra sociedad y, aparte de tres excepciones (Von Moos, Zellweger Uster y Landis \& Gyr), todas forman parte del mismo componente (cf. figura 9). Además, los vínculos están aún claramente articulados alrededor de los tres grandes bancos, que continúan ocupando un lugar central, y contribuyen por otro lado a las interconexiones entre las empresas MEM mismas: así, los tres interlocks que unen por ejemplo BBC a Sulzer en 1980 se apoyan únicamente sobre administradores externos a las dos sociedades (Hans Strasser, presidente de la SBS; Robert Holzach, presidente de la UBS y Oswald Aeppli, presidente del Crédit Suisse). Pero los interlocks entre las firmes MEM son igualmente significativos de mecanismos de coordinación y de control entre las 
empresas. En muchos casos, éstos resultan de un proceso de adquisición como, por ejemplo, la empresa Buss, ligada al grupo Georg Fischer en la que ha sido integrada en 1979, o Zellweger Uster, controlada por la familia Bechtler, e integrada en los años 1970 a la holding Hesta, igualmente bajo control de Bechtler; en cuanto a Cortaillod y Cossonay, sociedades que participan en el cártel suizo de cables, poseen aún tres miembros en común en 1980, y terminan por fusionarse en 1992.

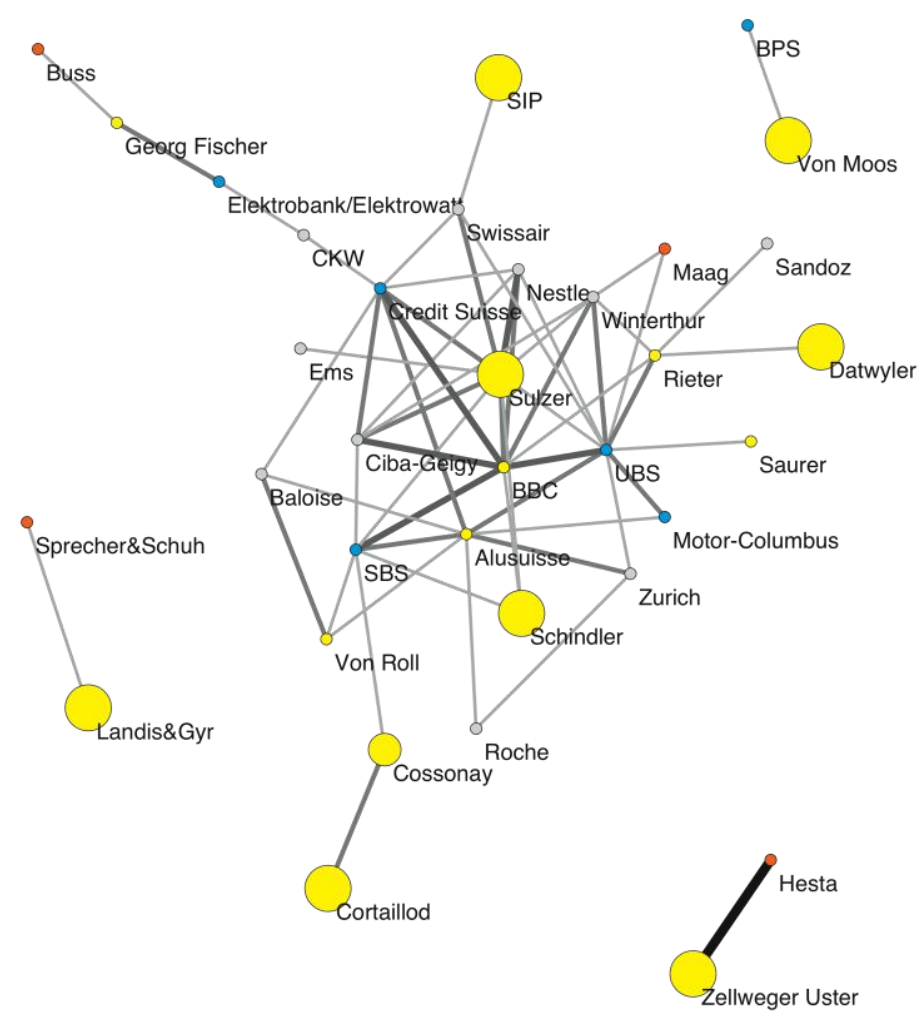

Figura 9. La sub-red de las 22 empresas MEM en 1980, 2-slices

La sub-red de las 22 empresas MEM desarrolla así las tres grandes características siguientes durante los decenios que siguen a la Primera Guerra mundial hasta los años 1980. En primer lugar, se hace cada vez más cohesivo y denso, pasando de un sistema de alianzas ancladas a nivel regional a una integración de vínculos a nivel nacional. En segundo lugar, las empresas MEM están fuertemente conectadas al sector bancario y financiero, constatación que viene a confirmar la importancia de este sector en el sistema de gobierno suizo, y que se explica por el papel que los bancos han jugado desde el final del siglo XIX en la financiación de las empresas. Si bien esta dimensión ha sido ya puesta en evidencia por otros autores (cf. Rusterholz 1985, Nollert 1998, Schnyder et al. 2005), y no representa, además, 
una especificidad del modelo helvético, nuestros resultados hacen emerger, no obstante, una nueva propiedad de la red: la fuerte centralidad de las empresas familiares. Volviendo al modelo de coordinación y de control propuesto por Scott, es posible entonces concluir que el caso de Suiza - en lo que concierne al sector MEM al menos - combina a la vez la versión del control por los bancos y la del control por las familias, aunque sea necesario más bien resaltar la importancia de la noción de cooperación entre las élites dirigentes puesto que los vínculos, como hemos visto, son a menudo de naturaleza recíproca. Finalmente, los interlocks intrasectoriales ganan progresivamente en importancia desde el periodo entre guerras con respecto a las interconexiones con el sector bancario y financiero, viniendo a confirmar la hipótesis de una coordinación patronal al menos parcialmente anclada en el sistema.

\section{Persistencia y disolución de los mecanismos de coordinación}

Hemos visto anteriormente que la sub-red MEM conoce una mutación profunda a fin de siglo, marcada por una fuerte decadencia de los interlocks entre las empresas y la significativa erosión del capitalismo familiar, cuyos principales factores explicativos han sido evocados. La evolución diferenciada de los vínculos por sector nos lleva no obstante a matizar y precisar esta afirmación (cf. tabla 5 infra). El declive de los interlocks resulta, en primer lugar, de la retirada del sector bancario, ligada a la liberación progresiva de los bancos en el sector industrial que se explica principalmente por las siguientes razones: una reorientación estratégica de las actividades de los bancos hacia los mercados bursátiles (cotizada en bolsa, fusiones y adquisiciones, fondos comunes de inversión) y la gestión de fortuna, en detrimento de la actividad tradicional de crédito, una extensión de las actividades en el campo asegurador, y una fuerte expansión en el mercado internacional (Schnyder et al. 2005 : 41-46). Esta evolución ha sido igualmente observada en otros países, especialmente en Alemania (ver por ejemplo Beyer 2002 y Höpner \& Krempel 2003), y ha llevado a los bancos a retirarse progresivamente de los consejos de administración en los que participaban. Así, en 2000, ni una sola de nuestras 22 firmas MEM sostiene vínculo múltiple con un gran banco (cf. figura 10 infra). Si bien la decadencia global de los interlocks resulta también, en segundo lugar, de una disminución de los vínculos entre las empresas industriales mismas, se observa sin embargo un mantenimiento significativo de los vínculos - múltiples y simples -dentro del sector MEM mismo: en efecto, las interconexiones entre las empresas MEM disminuyen menos fuertemente que las mantenidas con empresas pertenecientes a otras ramas. 


\begin{tabular}{|l|c|c|c|c|c|}
\hline & $\mathbf{1 9 1 0}$ & $\mathbf{1 9 3 7}$ & $\mathbf{1 9 5 7}$ & $\mathbf{1 9 8 0}$ & $\mathbf{2 0 0 0}$ \\
\hline Nivel promedio: MEM-MEM & 1,2 & 2,5 & 3,1 & 3,6 & 2,5 \\
\hline Nivel promedio: MEM-bancos & 1,4 & 2,5 & 2,7 & 3,2 & 1,5 \\
\hline $\begin{array}{l}\text { Nivel promedio: MEM-otros } \\
\text { sectores }\end{array}$ & 1,2 & 2,2 & 2,6 & 3,5 & 2,0 \\
\hline
\end{tabular}

Tabla 3. Nivel promedio de grado de las 22 empresas MEM, por sector.

La persistencia de los vínculos intrasectoriales puede interpretarse como una voluntad de las élites dirigentes de reforzar su sector de cara a un mercado cada vez más competitivo (Widmer 2009: 233). Esta hipótesis se ve reforzada por el hecho de que al final de los años 1990, las dos principales asociaciones de la rama, la ASM (Arbeitgeberverband schweizerischer Maschinen- und Metallindustrieller) y la VSM (Verein schweizerischer Maschinen-Industrieller) realizan un acercamiento administrativo y jurídico de sus respectivas estructuras que desemboca en la creación de Swissmem, organización que reagrupa a las dos asociaciones con el fin de defender mejor los intereses de la rama de cara a los otros sectores industriales (ver Widmer 2009 y David et al. 2009). Así, Georg Fischer está en 2000 ligada a SIG por cuatro miembros comunes, y a ABB por dos mismos administradores. La posición de Edwin Somm - miembro de los consejos de administración de las tres firmas, antiguo presidente de la ASM (1995-1998) y futuro presidente de ABB - en cuanto al hecho de reclutar administradores que participen en empresas del mismo sector muestra que los interlocks continúan presentando un interés para una parte de las élites MEM: en efecto, según él, «El reclutamiento de dirigentes conocedores de los productos y del mercado permite concentrar competencias » (declaración tomada de una entrevista en Widmer 2009 : 149). La figura 10 muestra otro grupo de empresas MEM ligadas por administradores comunes: Rieter está en efecto interconectada a Dätwyler y a Scintilla por un interlock doble. Su director general, Kurt Feller, ocupa especialmente un escaño en los consejos de las otras dos sociedades, además de presidir el consejo de Geberit, otra empresa del sector MEM. Ahora bien, Kurt Feller se distingue por una toma de posición abierta contra una gestión accionarial de la empresa (Widmer 2009: 256). Estos dos casos muestran que, por razones diferentes, ciertos dirigentes del sector MEM han sostenido activamente el mantenimiento de los interlocks intrasectoriales al final de siglo. 


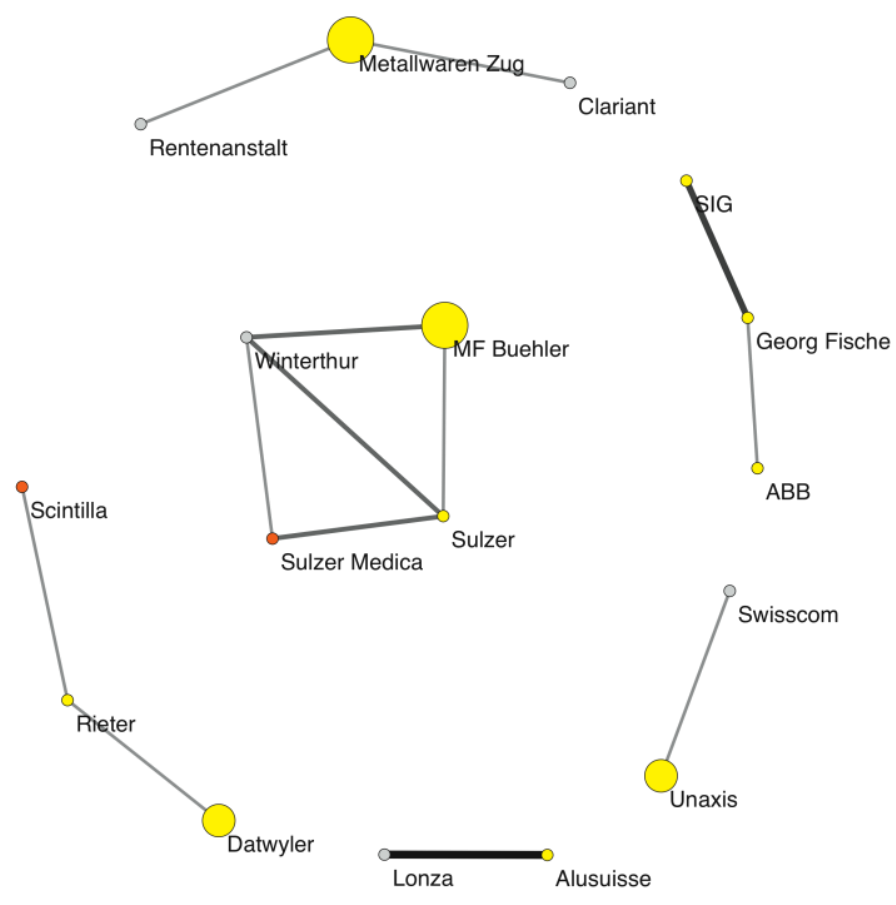

Figura 10. La sub-red de 22 empresas MEM en 2000, 2-slices.

\section{Conclusiones}

Hasta el presente, los estudios que abordan la red de las grandes empresas suizas se habían centrado sobre todo en el peso y rol de los bancos. Sin poner en cuestión el lugar central efectivamente ocupado por estas instituciones, nuestro análisis nos ha permitido poner en evidencia el lugar significativo y complementario que han tenido las empresas familiares a través del ejemplo de las grandes industrias del sector de las máquinas, de la electrotecnia y la metalurgia. En primer lugar, el análisis de la red interfirmas ha mostrado que hasta los años 1980, las empresas MEM desarrollan interlocks ( $y$ en menor medida, vínculos puramente familiares) cada vez más densos entre ellas mismas y con el resto de las 110 más grandes sociedades helvéticas: lejos de suplantar los vínculos familiares, estas interconexiones se apoyan entonces por el contrario, en gran parte, sobre las empresas familiares y sobre los dirigentes pertenecientes a las dinastías fundadoras o neo-fundadoras. En segundo lugar, estas firmas familiares están fuertemente conectadas a los bancos y a las instituciones financieras. El hecho de que los vínculos sean frecuentemente de naturaleza recíproca nos lleva, no obstante, a relativizar la hipótesis de un control formal ejercido por una u otra fracción 
(bank/family control model), y a subrayar preferentemente la dimensión de cooperación y coordinación entre las élites económicas helvéticas. Esta hipótesis se ve reforzada por el hecho de que las empresas del sector MEM desarrollan además en el curso del siglo fuertes interconexiones intrasectoriales, que contribuyen a regular la competencia. Estas implican esencialmente dos mecanismos. Pueden resultar, primero, de un proceso de adquisición, desembocando a veces en una fusión: en este caso, los interlocks cumplen una función de control. Pero se observan igualmente vínculos significativos de un mecanismo de cooperación entre firmas independientes que ejercen actividades similares o complementarias. Finalmente, la existencia de una red muy cohesiva de big linkers, formada a la vez de banqueros y de dirigentes familiares, nos incita además a mantener la hipótesis de cohesión de clase, que abre pistas a investigaciones posteriores: estas consistirían especialmente en invertir de manera sistemática la implicación de los dirigentes MEM en las asociaciones patronales y en la esfera política, a fin de poner en evidencia las otras vías utilizadas por esta élite para implementar la coordinación patronal.

La cohesión de las élites implicadas en el sector MEM, así como los mecanismos de cooperación utilizados entre ellas, son no obstante cuestionados durante los dos últimos decenios del siglo. Se observa en un principio la erosión del capitalismo familiar, ya perceptible al inicio de los años 1980. El hecho de que en ciertos casos, las familias a la cabeza de las sociedades MEM hayan sido excluidas por los bancos muestra que la cohesión entre las élites suizas puede dar lugar a relaciones conflictivas, favorecidas por los periodos de crisis. En segundo lugar, el crecimiento de inversionistas institucionales, el advenimiento del capitalismo financiero y la reorientación de las estrategias de empresa hacia la creación de valor accionista se tradujo en un distanciamiento de los bancos hasta entonces fuertemente implicados en las industrias, desembocando en el declive de los interlocks en el seno de la subred MEM. Estas mutaciones profundas deben matizarse puesto que se observa, por una parte, una relativa persistencia del capitalismo familiar en comparación con otros países $y$, por otra parte, un reajuste de los vínculos en el sector MEM, que muestran que los mecanismos tradicionales de coordinación y de control en el interior de las élites suizas aún subsisten en parte.

Finalmente, el análisis de red nos ha permitido poner en evidencia la integración y la evolución de las firmas familiares para el caso de Suiza en un sistema capitalista más amplio, e identificar así tendencias generales más allá del estudio de caso. En contrapartida, el hecho de estudiar un amplio grupo de empresas, y además a largo plazo, presenta el riesgo de perder en análisis cualitativo. Este límite puede, no 
obstante, ser sobrepasado integrando al análisis de red estudios de caso en profundidad, siendo en efecto ambos enfoques perfectamente compatibles. Esta investigación se desarrollará posteriormente en esta perspectiva.

\section{Bibliografía}

Batsch, Laurent (2002). Le capitalisme financier. Paris : La Découverte. BBC (1966). Brown Boveri -75 ans: 1891-1966. Baden : Brown Boveri.

Berle, Adolf et Gardimer Means (1932). The Modern Corporation and Private Property. New York : Maccmillan.

Beyer, Jürgen (2002). Deutschland AG a.D: Deutsche Bank, Allianz und das Verflechtungszentrum grosser deutscher Unternehmen. MPIfG Working Paper 02(4).

Billeter, Geneviève (1985). Le pouvoir patronal. Les patrons des grandes entreprises suisses des métaux et des machines. Genève : Droz.

Casson, Mark (2000). Enterprises and Leadership. Studies on Firms, Markets and Networks. Mass : Elgar, Cheltenham and Northhampton.

Catrina, Werner (1991). BBC: Glanz, Krise, Fusion : 1891-1991, von Brown Boveri zu $A B B$. Zürich, Wiesbaden : Orell Füssli.

Chandler, Alfred (1990). Scale and Scope. The Dynamics of Industrial Capitalism. Cambridge (Mass.) : The Belknap Press of Harvard University Press.

Chandler, Alfred (1977). The Visible Hand. The Managerial Revolution in American Business. Cambridge (Mass.) : The Belknap Press of Harvard University Press.

Colli, Andrea (2010 à paraítre). «Business History in Family Business Studies: from Neglect to Cooperation? » Journal of Family Business Management.

Colli, Andrea (2003). The History of Family Business, 1850-2000. Cambridge: Cambridge University Press.

Colli, Andrea et Mary Rose (2008). « Family Business. » In Jones, G. et J. Zeitlin, The Oxford Handbook of Business History, Oxford : University Press.

Cortat, Alain (dir) (2010). Contribution à une histoire des cartels en Suisse. Neuchátel : Alphil.

Cortat, Alain (2009). Un cartel parfait. Les cábleries et tréfileries de Cossonay (1898-1987) et les cábles de Cortaillod (1868-1970). Neuchátel : Alphil.

Dätwyler (1965). Dätwyler, portrait d'une entreprise. Altdorf : Dätwyler.

Daumas, Jean-Claude (dir.) (2003). Le capitalisme familial: logiques et trajectoires. Actes de la journée d'études de Besançon du 17 janvier 2002, Presses universitaires franc-comtoises.

David, Thomas, André Mach, Martin Lüpold et Gerhard Schnyder (2011 à paraítre). De la «forteresse des Alpes » à la valeur actionnariale : Histoire du gouvernement $d^{\prime}$ entreprise suisse au $20^{e}$ siècle. Zurich : Seismo.

Dictionnaire Historique Suisse (DHS). Articles disponibles en ligne (www.hls-dhsdss.ch).

Ernst \& Young (2005). Les entreprises familiales suisses et la bourse. Ernst \& Young SA.

Ginalski, Stéphanie (2010). «Business Elites and Family Capitalism. The Case of 
the Swiss Metallurgy Industry During the 20th Century ». Papier présenté à la 14th Annual Conference of the European Business History Association 2010, Glasgow.

Giovanoli, Fritz (1939). Libre Suisse, Voici tes maítres. Brochure du Parti Socialiste, Zurich : Ed. Jean Christophe.

Hall, Peter et David Soskice (2001). «An Introduction to Varieties of Capitalism. » In Hall, Peter et David Soskice, Varieties of Capitalism: the Institutional Foundations of Comparative Advantage, Oxford : Oxford University Press : 1-68.

Holliger, Carl M. (1974). Die Reichen und die Superreichen in der Schweiz. Hamburg : Hoffmann und Campe.

Höpflinger, François (1978). L'empire suisse. Genève : Grounauer.

Höpner, Martin et Lothar Krempel (2003). The Politics of the German Company Network. MPIfG Working Paper 9.

James, Harold (2006). Family capitalism. Wendels, Haniels, Falcks and the Continental European Model. Cambridge, London : Harvard University Press.

Joly, Hervé (2008). Diriger une grande entreprise française au XXe siècle : modes de gouvernance, trajectoires et recrutement. Mémoire inédit présenté pour I'habilitation à diriger des recherches, Vol. 1. Ecoles des Hautes études en sciences sociales.

La Porta Rafael, Florencio Lopez-de-Sialnes, Andrei Shleifer et Robert Vishny (1999). «Corporate Ownership Around the World. » The Journal of Finance 54(2) : 471-517.

Lazonick, William et Mary O'Sullivan (2000). «Maximizing Shareholder Value : a New Ideology for Corporate Governance. » Economy and Society 29(1): 13-35.

Lemercier, Claire (2005). «Analyse de réseaux et histoire de la famille : une rencontre encore à venir ? » Anales de démographie historique 1 : 7-31.

Lordon, Frédéric (2000). "La "création de la valeur" comme rhétorique et comme pratique. Généalogie et sociologie de la "valeur actionnariale". » L'année de la régulation 4: 117-165.

Lüpold, Martin (2009). Der Ausbau der «Festung Schweiz». Aktienrecht und Corporate Governance in der Schweiz, 1881-1961. Thèse de doctorat non publiée, Université de Zurich.

Mills, Wright (1969). L'élite du pouvoir. Paris : Maspero.

Mizruchi, Mark (1996). «What Do Interlocks Do ? An Analysis, Critique, and Assessment of Research on Interlocking Directorates. » Annual Review of Sociology 22: 271-298.

Nollert, Michael (1998). «Interlocking Directorates in Switzerland: A Network Analysis. » Revue suisse de sociologie 24(1) : 31-58.

Nooy, Wouter de, Andrej Mrvar et Vladimir Batagelj (2005). Exploratory Social Network Analysis with Pajek. New York : Cambridge University Press.

Paquier, Serge (2001). «Swiss Holding Companies from the Mid-Nineteenth Century to the Early 1930s: the Forerunners and Subsequent Waves of Creations. » Financial

History Review 8(2): 163-182.

Pollux (1944). Trusts in der Schweiz. Die schweizerische Politik im Schlepptau der Hochfinanz. Zurich : Verein für wirtschaftliche Studien.

Rebérioux, Antoine (2005). «Les fondements microéconomiques de la valeur 
actionnariale : Une revue critique de la littérature. » Revue économique 56(1) : 5175.

Rusterholz, Peter (1985). «The Banks in the Centre : Integration in Decentralized Switzerland. » In Stokman, Frans N. et al., Networks of Corporate Power. A Comparative Analysis of Ten Countries, Cambridge : Polity Press . 131-147.

Schnyder, Gerhard (2007). Corporate Governance Reform in Switzerland: Law, Politics and the Social Organization of Business, 1965-2005. Thèse de doctorat non publiée, Université de Lausanne.

Schnyder, Gerhard, Martin Lüpold, André Mach et Thomas David (2005). The Rise and Decline of the Swiss Company Network During the $20^{\text {th }}$ Century. Travaux de Science Politique 22, Université de Lausanne.

Schreiner, Jean-Paul (1984). «Le capital financier et le réseau des liaisons personnelles entre les principales sociétés en Suisse. » Revue d'économie industrielle 29 :78-95.

Schröter, Harm G. (1999). «Small European Nations : Cooperative Capitalism in the Twentieth Century. » In Chandler, Alfred D. et al., Big Business and the Wealth of Nations, Cambridge : Cambridge University Press : 176-204.

Scott, John (1985). «Theoretical Framework and Research Design. »In Stokman, Frans N. et al., Networks of Corporate Power. A Comparative Analysis of Ten Countries, Cambridge : Polity Press : 1-19.

Stokman, Frans N. et Frans W. Wasseur (1985). « National Networks in 1976 : A Structural Comparison. » In Stokman, Frans N. et al., Networks of Corporate Power. A Comparative Analysis of Ten Countries, Cambridge : Polity Press : 20-44.

Stokman, Frans N., Rolf Ziegler et John Scott (1985). Networks of Corporate Power. A Comparative Analysis of Ten Countries. Cambridge : Polity Press.

UBS (1980). Les principales entreprises de Suisse. Zurich : UBS.

Useem, Michael (1996). Investor Capitalism. How Money Managers Are Changing the Face of Corporate America. New York : BasicBooks.

Useem, Michael (1984). The Inner Circle: Large Corporations and the Rise of Business Political Activity in the US and the UK. New York : Oxford University Press.

Widmer, Frédéric (2009). La coordination des dirigeants économiques face à la financiarisation. Gouvernance d'entreprise, relations industrielles et élites dirigeantes dans l'industrie suisse des machines, de l'électrotechnique et de la métallurgie (1970-2008). Thèse de doctorat non publiée, Université de Lausanne.

Windolf, Paul (2009). «Coordination and Control in Corporate Network: United States and Germany in Comparison, 1896-1938. » European Sociological Review 25(4) : 443-457.

Windolf, Paul et Michael Nollert (2001). « Institutionen, Interessen, Netzwerke : Unternehmensverflechtung im internationalen Vergleich. » Politische Vierteljahresschrift $42:$ 51-78.

Zeitlin, Maurice, Lynda Ann Ewen et Richard Earl Ratcliff (1974). «"New Princes" for Old? The Large Corporation and the Capitalist Class in Chile. » The Amercian Journal of Sociology 80(1) : 87-123. 
Anexo 1. Lista de las 22 empresas MEM y presencia familiar

\begin{tabular}{|c|c|c|c|c|c|c|c|}
\hline & 1910 & 1937 & 1957 & 1980 & 2000 & $\begin{array}{c}\text { Familias } \\
\text { fundadoras / } \\
\text { fundadores }\end{array}$ & $\begin{array}{l}\text { Otras } \\
\text { familias }\end{array}$ \\
\hline AIAG/Alusuisse & $\mathrm{F}$ & $\mathrm{F}$ & $M$ & $\mathrm{~N}$ & $\mathrm{~N}$ & Naville, Huber & - \\
\hline BBC/ABB & $\mathrm{F}$ & M & $\mathrm{F}$ & $\mathrm{N}$ & $\mathrm{N}$ & Brown, Boveri & - \\
\hline Bobst & $\mathrm{F}$ & $\mathrm{F}$ & $\mathrm{F}$ & $\mathrm{F}$ & $\mathrm{F}$ & Bobst & - \\
\hline Bucher & $\mathrm{F}$ & $\mathrm{F}$ & $\mathrm{F}$ & $\mathrm{F}$ & $\mathrm{F}$ & Bucher & - \\
\hline Cortaillod & $\mathrm{F}$ & $\mathrm{F}$ & $\mathrm{F}$ & $\mathrm{F}$ & - & $\begin{array}{l}\text { Borel, Berthoud, } \\
\text { de Coulon }\end{array}$ & - \\
\hline Cossonay & $M$ & $\mathrm{~F}$ & $\mathrm{~F}$ & $M$ & - & J. M. Aubert & De coulon \\
\hline Dätwyler & $\mathrm{N}$ & $\mathrm{F}$ & $\mathrm{F}$ & $\mathrm{F}$ & M & $\begin{array}{l}\text { Grupo de interés } \\
\text { alemán }\end{array}$ & Dätwyler \\
\hline Georg Fischer & $\mathrm{F}$ & $\mathrm{F}$ & M & $\mathrm{N}$ & $\mathrm{N}$ & Fischer & Homberger \\
\hline Hasler/Ascom & $\mathrm{F}$ & $\mathrm{F}$ & $\mathrm{N}$ & $\mathrm{N}$ & $\mathrm{N}$ & Hasler & - \\
\hline Landis\&Gyr & $\mathrm{F}$ & $\mathrm{F}$ & $\mathrm{F}$ & $\mathrm{F}$ & - & Landis, Gyr & - \\
\hline Metallwaren Zug & $\mathrm{F}$ & $\mathrm{F}$ & $\mathrm{F}$ & $\mathrm{F}$ & $\mathrm{F}$ & Weber & Stöckli \\
\hline MF Bühler & $\mathrm{F}$ & $\mathrm{F}$ & $\mathrm{F}$ & $\mathrm{F}$ & $\mathrm{F}$ & Bühler & - \\
\hline $\begin{array}{l}\text { Oerlikon- } \\
\text { Bührle/Unaxis }\end{array}$ & $\mathrm{N}$ & $\mathrm{F}$ & $\mathrm{F}$ & $\mathrm{F}$ & $M$ & $\begin{array}{l}\text { Grupo de } \\
\text { industriales } \\
\text { suizos }\end{array}$ & Bührle \\
\hline Rieter & $\mathrm{F}$ & M & M & $\mathrm{N}$ & $\mathrm{N}$ & Rieter & Corti \\
\hline Saurer & $\mathrm{F}$ & M & M & $\mathrm{N}$ & $\mathrm{N}$ & Saurer & - \\
\hline Schindler & $\mathrm{F}$ & $\mathrm{F}$ & $\mathrm{F}$ & $\mathrm{F}$ & $\mathrm{F}$ & Schindler & - \\
\hline SIG & $\mathrm{F}$ & $\mathrm{F}$ & $\mathrm{F}$ & $\mathrm{N}$ & $\mathrm{N}$ & Neher & Frey \\
\hline $\begin{array}{l}\text { SIP consejo de } \\
\text { administracion }\end{array}$ & $F$ & $\mathrm{~F}$ & $\mathrm{~F}$ & $\mathrm{~F}$ & $\mathrm{~F}$ & Rive, Thury & $\begin{array}{l}\text { Turrettini, } \\
\text { Suchet }\end{array}$ \\
\hline Sulzer & $\mathrm{F}$ & $\mathrm{F}$ & $\mathrm{F}$ & $\mathrm{F}$ & $\mathrm{N}$ & Sulzer & - \\
\hline Von Moos & $\mathrm{F}$ & $\mathrm{F}$ & $\mathrm{F}$ & $\mathrm{F}$ & - & Von Moos & - \\
\hline Von Roll & $\mathrm{F}$ & $\mathrm{F}$ & M & $\mathrm{N}$ & $\mathrm{N}$ & Von Roll & Dübi \\
\hline $\begin{array}{l}\text { Zellweger } \\
\text { Uster/Luwa }\end{array}$ & $\mathrm{F}$ & $M$ & $M$ & $\mathrm{~F}$ & $\mathrm{~F}$ & A. Zellweger & Bechtler \\
\hline
\end{tabular}

F : Capitalismo familiar «fuerte» : la familia ocupa una funcion principal en la empresa (presidente del consejo de administración, administrador-delegado o director ejecutivo)

M : Capitalismo familiar « medio » : la familia participa en el consejo de administración o es accionista mayoritaria, pero no ocupa funcion principal

$\mathrm{N}$ : La empresa no es una empresa familiar 